\title{
Transient Convection Due to Imposed Heat Flux: Application to Liquid-Acquisition Devices
}

Walter M.B. Duval, David J. Chato, and Michael P. Doherty

Glenn Research Center, Cleveland, Ohio 


\section{NASA STI Program . . . in Profile}

Since its founding, NASA has been dedicated to the advancement of aeronautics and space science. The NASA Scientific and Technical Information (STI) program plays a key part in helping NASA maintain this important role.

The NASA STI Program operates under the auspices of the Agency Chief Information Officer. It collects, organizes, provides for archiving, and disseminates NASA's STI. The NASA STI program provides access to the NASA Aeronautics and Space Database and its public interface, the NASA Technical Reports Server, thus providing one of the largest collections of aeronautical and space science STI in the world. Results are published in both non-NASA channels and by NASA in the NASA STI Report Series, which includes the following report types:

- TECHNICAL PUBLICATION. Reports of completed research or a major significant phase of research that present the results of NASA programs and include extensive data or theoretical analysis. Includes compilations of significant scientific and technical data and information deemed to be of continuing reference value. NASA counterpart of peer-reviewed formal professional papers but has less stringent limitations on manuscript length and extent of graphic presentations.

- TECHNICAL MEMORANDUM. Scientific and technical findings that are preliminary or of specialized interest, e.g., quick release reports, working papers, and bibliographies that contain minimal annotation. Does not contain extensive analysis.

- CONTRACTOR REPORT. Scientific and technical findings by NASA-sponsored contractors and grantees.
- CONFERENCE PUBLICATION. Collected papers from scientific and technical conferences, symposia, seminars, or other meetings sponsored or cosponsored by NASA.

- SPECIAL PUBLICATION. Scientific, technical, or historical information from NASA programs, projects, and missions, often concerned with subjects having substantial public interest.

- TECHNICAL TRANSLATION. Englishlanguage translations of foreign scientific and technical material pertinent to NASA's mission.

Specialized services also include creating custom thesauri, building customized databases, organizing and publishing research results.

For more information about the NASA STI program, see the following:

- Access the NASA STI program home page at http://www.sti.nasa.gov

- E-mail your question to help@sti.nasa.gov

- Fax your question to the NASA STI Information Desk at 443-757-5803

- Phone the NASA STI Information Desk at 443-757-5802

- Write to: STI Information Desk NASA Center for AeroSpace Information 7115 Standard Drive Hanover, MD 21076-1320 


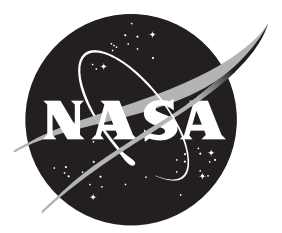

\section{Transient Convection Due to Imposed Heat Flux: Application to Liquid-Acquisition Devices}

Walter M.B. Duval, David J. Chato, and Michael P. Doherty

Glenn Research Center, Cleveland, Ohio

Prepared for the

49th Aerospace Sciences Meeting

sponsored by the American Institute of Aeronautics and Astronautics

Orlando, Florida, January 4-7, 2011

National Aeronautics and

Space Administration

Glenn Research Center

Cleveland, Ohio 44135 


\section{Acknowledgments}

This work was performed in support of the Cryogenic Fluid Management program at the NASA Glenn Research Center. The computations were performed using the Columbia supercomputer (Silicon Graphics International Corp. Altix) at the NASA Ames Research Center's NASA Advanced Supercomputing facility.

Level of Review: This material has been technically reviewed by technical management.

Available from

NASA Center for Aerospace Information 7115 Standard Drive

Hanover, MD 21076-1320
National Technical Information Service 5301 Shawnee Road Alexandria, VA 22312

Available electronically at http://www.sti.nasa.gov 


\title{
Transient Convection Due to Imposed Heat Flux: Application to Liquid-Acquisition Devices
}

\author{
Walter M.B. Duval, David J. Chato, and Michael P. Doherty \\ National Aeronautics and Space Administration \\ Glenn Research Center \\ Cleveland, Ohio 44135
}

\section{Summary}

A model problem is considered that addresses the effect of heat load from an ambient laboratory environment on the temperature rise of liquid nitrogen inside an enclosure. This model has applications to liquid acquisition devices inside the cryogenic storage tanks used to transport vapor-free propellant to the main engine. We show that heat loads from $Q=0.001$ to $10 \mathrm{~W}$, with corresponding Rayleigh numbers from $R a=10^{9}$ to $10^{13}$, yield a range of unsteady convective states and temperature rise in the liquid. The results show that $Q=1$ to $10 \mathrm{~W}\left(R a=10^{12}\right.$ to $\left.10^{13}\right)$ yield temperature distributions along the enclosure height that are similar in trend to experimental measurements. Unsteady convection, which shows selfsimilarity in its planforms, is predicted for the range of heat-load conditions. The onset of convection occurs from a free-convection-dominated base flow that becomes unstable against convective instability generated at the bottom of the enclosure while the top of the enclosure is convectively stable. A number of modes are generated with small-scale thermals at the bottom of the enclosure in which the flow selforganizes into two symmetric modes prior to the onset of the propagation of the instability. These symmetric vertical modes transition to asymmetric modes that propagate as a traveling-wave-type motion of convective modes and are representative of the asymptotic convective state of the flow field. Intense vorticity production is created in the core of the flow field due to the fact that there is shear instability between the vertical and horizontal modes. For the higher Rayleigh numbers, $10^{12}$ to $10^{13}$, there is a transition from a stationary to a nonstationary response time signal of the flow and temperature fields with a mean value that increases with time over various time bands and regions of the enclosure.

\subsection{Introduction}

The investigation of the effect of heat flux applied at the bottom boundary of an enclosure, which contains cryogenic liquid nitrogen, to determine its temperature response requires knowledge of the dynamical state of the system when there is no applied heat flux; the enclosure is located inside an ambient laboratory environment. The no-applied-heat-flux case is necessary since it represents the effect of the heat flow from the background laboratory environment on the thermodynamic state of the liquid inside the enclosure. As part of a broader program to investigate heat entrapment effects in liquid acquisition devices, Bolshinskiy et al. (Refs. 1 and 2) conducted an experiment to measure the effect of background heat flow from a laboratory environment on the temperature rise of liquid nitrogen inside an enclosed container (Dewar). The results showed that, when no heat flux was applied directly at the bottom boundary, temperature rise occurred at various positions along the vertical height of the enclosure. A model problem is addressed to obtain insight into the meaning of the temperature measurements (in no-screen, no-heater conditions, Ref. 1) for the sole condition of heat flow to the system from the background laboratory environment.

To determine a suitable range of parameters, we estimated a range of typical heat loads caused by the thermal background radiation, which yielded a conservative heat load of $Q=0.001 \mathrm{~W}$ to a typical maximum value of $Q=10 \mathrm{~W}$. We approximated the problem as a rectangular cross section of a cylinder; this was convenient since, at the lowest heat load $(Q=0.001 \mathrm{~W})$, the Rayleigh number $R a$ is on the order of $10^{9}$ and flow asymmetry occurs in this system for $R a$ on the order of $10^{7}$, as shown by Duval, Chato, and Doherty (Ref. 3). This implies a full transient calculation for a three-dimensional cylinder. However, a rectangular model provides an approximation to the system that allows the transient dynamics to be 
investigated beyond asymmetry. The dynamics of the system for $R a=1$ to $10^{8}$ has been considered for an aspect ratio of $A r=1$ (Ref. 3), and a short-time solution for $R a=10^{9}$ is presented for $A r=3.24$ (Ref. 3). Herein, we consider the asymptotic dynamics for $R a=10^{9}$ and $A r=3.24$, and we extend the calculations to $R a=10^{13}$ for the highest heat-load condition. We show that at the highest heat load, the model predicts temperature magnitude comparable to that in the experiments (Refs. 1 and 2). In addition, the model shows the dynamical state of the accompanying flow field, which was not accessible during the experiments since only temperatures inside the system were measured (Refs. 1 and 2).

In analogy to our model problem of a cryogenic liquid inside an enclosure that has a large height and that absorbs heat flux predominantly from its bottom and top boundaries, there have been a number of investigations on the convective instability inside enclosures heated from below with prescribed temperature boundary conditions on the bottom and top boundaries, which lend insight into our model problem. Townsend (Ref. 4) showed that convection near a heated horizontal surface depends on the layer near the heated surface (independent of the geometrical height of the enclosure) and is determined by the heat flux, viscosity, and conductivity of the fluid. Townsend described the formation of thermals on the heated surface as rising columns of hot air from the edge of the conduction layer. A phenomenological theory was put forth by Howard (Ref. 5) who postulated that convection consists of a conductive phase, during which the conduction boundary layer is formed, followed by a short time interval, during which the thermals break off. Convective instability, or the formation of thermals, occurs after a time $t^{o}$ that is shorter than the thermal diffusion time $H^{2} / \alpha$, where $H$ is the enclosure height and $\alpha$ is the thermal diffusivity. However, the thermals break away at a time that is short in comparison to the conductive period $t^{\circ}$. In addition, Howard (Ref. 5) showed that the mean temperature profile, based on the idea of marginal stability of the mean flow, depends on the thermal boundary layer thickness $\delta$ when it becomes unstable (in which the local Rayleigh number is based on $\delta$ ) and shows reasonable agreement with experimental data.

A number of two-dimensional numerical and experimental investigations of convective instability of flows inside enclosures that are heated from below consider the short-time evolution of the instability (Refs. 6 to 9) instead of the statistically steady regime (Ref. 10) for long times. Elder (Ref. 6) showed that a HeleShaw cell can be used to simulate, experimentally and computationally, two-dimensional flow in a porous medium within the context of flow in a homogeneous horizontal slab that is heated from below. When the approximation of a Hele-Shaw cell was used, numerical prediction of unsteady convection (Ref. 7) inside an enclosure in which the width of the heating zone at the base can be adjusted showed that the first motion is a set of eddies growing on opposite ends of the local heating zones. As the instability evolves, additional eddies are formed in the central region of the heating zone. For a long heating zone that is approximately the horizontal length of the slab, the initial motion of a pair of end cells followed by successive growth of a string of cells above the heater is similar to the case of a short heating zone. These events are phenomenologically similar to the short-time prediction of our model for the initiation of convective instability.

For a gravitationally unstable layer of viscous fluid initially hot below and cold above a horizontal plane, Elder (Ref. 8) showed that the scale of the motion is set by the thickness of the interface $\delta$ and is independent of the vertical distance $H$ of the horizontal plane in agreement with Townsend's (Ref. 4) findings. The amplification process of the disturbance in the interface is shown to be similar for the flow through a porous medium and for a viscous fluid inside a Hele-Shaw cell with impermeable boundaries. Experimental observation (Ref. 8) confirming numerical prediction shows that the instability develops as an array of blobs above a lower surface in a proto-sublayer. The disturbance remains embedded in the protosublayer until it reaches a finite amplitude. Similar events for short-time dynamics are shown to occur in our model for Rayleigh numbers on the order of $10^{12}$. The effect of various types of disturbance heat sources at the bottom boundary - namely, random, spatially varying, and constant - show similar developments of the instability (Ref. 8). This implies that the instability can be induced with a constant heat source as shown in our computational model. The development of the proto-sublayer is shown to be similar to the phenomenological description of the sublayer proposed by Howard (Ref. 5): that the mean temperature profile depends on the boundary layer thickness of the sublayer in which conduction effects dominate.

Elder (Ref. 9) shows that using one-dimensional mean field equations to model the flow development of the proto-sublayer can simulate two-dimensional numerical models. The spatial means are taken over a 
horizontal plane in the mean field equations, and the simulation is shown for Rayleigh numbers on the order of $10^{5}$. Even though Elder's numerical simulation (Refs. 7 and 8) captures the growth of cells in the flow field as the convective instability evolves, the temperature field shows that thermals are roughly represented by blobs; this is also shown experimentally for two-dimensional flows simulated with a Hele-Shaw cell configuration. The resolution of mushroomlike thermals exhibiting a blunted nearly hemispherical cap was captured in the experiments by Sparrow, Husar, and Goldstein (Ref. 11), which used water inside a threedimensional enclosure heated along a horizontal surface. They showed that thermals are generated periodically in time at fixed sites and that the breakup Rayleigh number based on the boundary layer thickness of the conduction layer is a constant, which validates a prediction by Howard (Ref. 5). Even though, for the short-time development of convective instability (in particular the proto-sublayer (Ref. 8)), the preceding works show trends that are similar to those of our model, for the long-time-scale asymptotic dynamics, we show herein that the dynamical state of the system is a traveling-wave-type motion of convective modes, which damps the evolution of thermals near the bottom boundary.

In the following sections, the formulation of the basic physics of the problem and discussion of the numerical solution are presented. Then, the global dynamics of the flow field - showing the growth of thermals, the transition to asymmetry, and the traveling-wave-type motion of the convective modes-are presented. Next, the flow field is probed at various fixed points to show time histories of the flow and temperature fields. Finally, we identify the range of heat load from the ambient laboratory environment, showing predicted temperature magnitudes that are comparable to those of the experiments.

\subsection{Formulation}

The model, which addresses the effect of the external heat load $Q$ from an ambient laboratory environment at temperature $T_{\infty}=293 \mathrm{~K}$ on the temperature rise of saturated liquid nitrogen, initially at $T_{A}=77 \mathrm{~K}$, inside an enclosure is shown in Figure 1. The heat load $Q$ transmits constant heat flux $q^{\prime \prime}$ on the boundaries of the enclosure with equal heat flux absorption on the bottom and top $\left(q_{b}{ }^{\prime \prime}=q_{t}{ }^{\prime \prime}\right)$, whereas the sidewall heat flux $q_{s}$ " is assumed to be small, $q_{s} "<<q_{b}$ ", since insulation was used at the side boundaries in these experiments (Refs. 1 and 2) to investigate heat entrapment effects inside liquid acquisition devices. The figure shows the locations of points inside the enclosure $\left(x_{p}, y_{p}\right)$ that allow

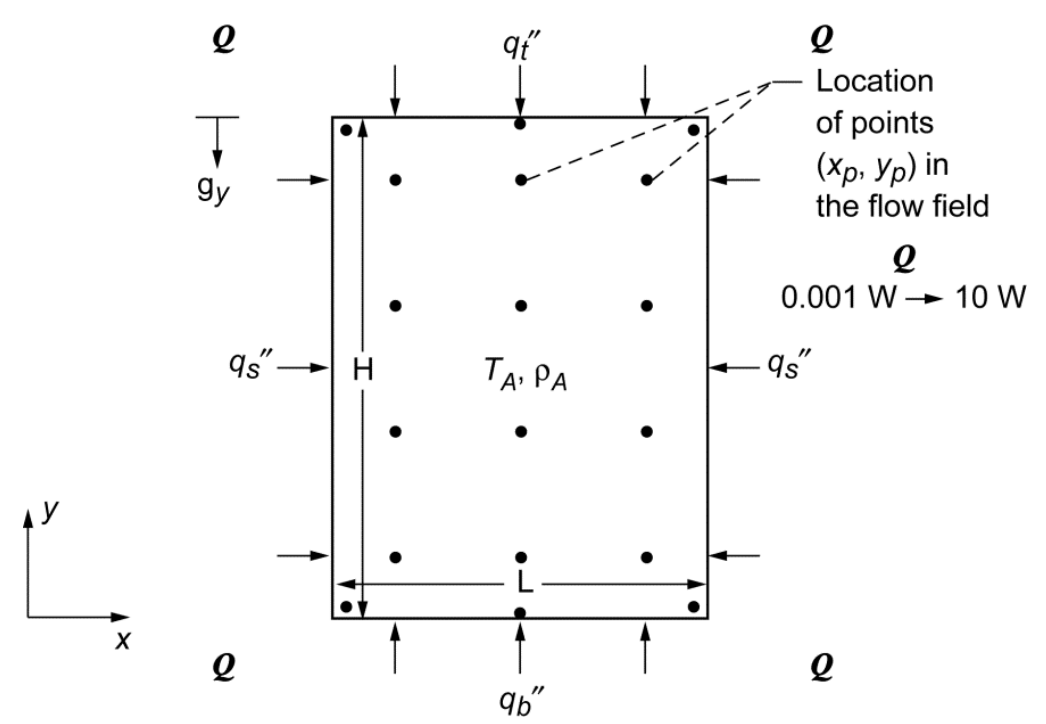

Figure 1.-Physical description of cryogenic fluid (ambient temperature, $T_{A}$, and density, $\rho_{A}$ ) inside an enclosure absorbing surface heat flux, at the bottom, sides, and top $\left(q_{b} ", q_{s} "\right.$, and $\left.q_{t}{ }^{\prime \prime}\right)$, from ambient environment heat flow, $Q$. Location of points in the flow field are denoted as $\left(x_{p}, y_{p}\right)$. 
probing of the time history of the flow and temperature fields similar to the experimental measurement points. The maximum heat load absorbed from the ambient owing to background thermal radiation can be estimated to be on the order of $10 \mathrm{~W}$, whereas a minimum conservative value is assumed to be $0.001 \mathrm{~W}$. The absorption of an infinitesimal heat load $Q$ through the boundaries of the large enclosure with height $H=61.9 \mathrm{~cm}$, approximately 3 times its horizontal length, $L=19.1 \mathrm{~cm}$, drives the system off equilibrium.

A deviation from equilibrium conditions will cause an increase in temperature given by

$$
\frac{D T}{D t}=\alpha \nabla^{2} T
$$

which can give rise to fluid motion owing to its coupling with the body force $\left(g_{y}=n \mathrm{~g}_{\mathrm{o}}\right)$ through the density field. The body force is directed downward vertically, in which $n$ represents the various gravitational levels of the Earth $(n=1)$, Moon $(n=1 / 6)$, or Mars $(n=1 / 3)$, and $g_{o}$ is the gravitational acceleration on Earth. For an incompressible Boussinesq fluid (where $\vec{V}$ is the velocity vector field),

$$
\nabla \cdot \vec{V}=0
$$

When the density $\rho$ is independent of pressure but is a function of temperature, the density can be given as an equation of state:

$$
\rho=\rho\left(T_{A}\right)[1-\beta \Delta T]
$$

where $\beta=-(1 / \rho)(\partial \rho / \partial T)_{p}$ is the coefficient of thermal expansivity, the subscript $p$ indicates pressure, and $\Delta T=T-T_{A}$ is the temperature difference. The motion of the fluid satisfies

$$
\frac{D \vec{V}}{D t}=-\frac{\nabla p}{\rho}+v \nabla^{2} \vec{V}-\beta \Delta T n \mathrm{~g}_{\mathrm{o}}
$$

where $t$ is time and $p$ is pressure.

The dynamical equations of motion (Eqs. (1), (2), and (4)) satisfy the initial condition that liquid nitrogen is at saturation:

$$
t=0, \quad T(x, y, 0)=T_{A}
$$

as well as the no-slip boundary condition along the boundary $\Gamma$ of the enclosure,

$$
t>0, \quad \vec{V}=0 \text { on } \Gamma
$$

Prescribed heat flux conditions are imposed along the bottom and top boundaries $\Gamma$ of the enclosure:

$$
\begin{aligned}
& y=0, \forall x, \quad q^{\prime \prime}=q_{b}^{\prime \prime}, \quad \partial T /\left.\partial y\right|_{y=0}=-q_{b}^{\prime \prime} / \kappa \\
& y=H, \forall x, \quad q^{\prime \prime}=q_{t}^{\prime \prime}, \quad \partial T /\left.\partial y\right|_{y=H}=-q_{t}^{\prime \prime} / \kappa
\end{aligned}
$$

and along the left and right walls,

$$
x=0, \forall y, \quad q^{\prime \prime}=q_{s}^{\prime \prime}, \quad \partial T /\left.\partial x\right|_{x=0}=-q_{s}^{\prime \prime} / \kappa
$$




$$
x=L, \forall y, \quad q^{\prime \prime}=q_{s}^{\prime \prime}, \quad \partial T /\left.\partial x\right|_{x=L}=-q_{s}^{\prime \prime} / \kappa
$$

where $\kappa$ is the thermal conductivity.

Since the top heat flux $q_{t}^{\prime \prime}$ has been shown to stabilize the flow (Ref. 3), fluid motion is generated by either natural convection due to the wall heat flux $q_{s}^{\prime \prime}$ or by convective instability due to the bottom heat flux $q_{b}^{\prime \prime}$. Since there is a threshold value on convective instability determined by $q_{b}^{\prime \prime}$ prior to its onset, a natural convection base flow is always generated owing to the finite heat absorption $q_{s}^{\prime \prime}$ at the wall. This base flow is independent of the heat flux absorbed at the top and bottom boundaries.

\subsection{Scaling Analysis and Computational Method}

For a computational solution of the dynamical equations of motion (Eqs. (1), (2), and (4)), the vector momentum equation (Eq. (4)) can be transformed to a scalar equation for the vorticity field for twodimensional flow. A single vorticity component in the $z$ direction is defined as

$$
\xi=\frac{\partial \mathrm{v}}{\partial x}-\frac{\partial u}{\partial y}
$$

where $\mathrm{v}$ and $u$ are the vertical and horizontal components of velocity, respectively. The resulting vorticity equation — when scaled using the characteristic length, time, and velocity $\left(L, L^{2} / \alpha\right.$, and $\left.\alpha / L\right)$ - becomes

$$
\frac{\partial \xi^{*}}{\partial t^{*}}+\left(u^{*} \frac{\partial \xi^{*}}{\partial x^{*}}+\mathrm{v}^{*} \frac{\partial \xi^{*}}{\partial y^{*}}\right)=\operatorname{Pr}\left(\frac{\partial^{2} \xi^{*}}{\partial x^{* 2}}+\frac{\partial^{2} \xi^{*}}{\partial y^{* 2}}\right)+\operatorname{Ra} \operatorname{Pr} \frac{\partial T^{*}}{\partial x^{*}}
$$

which implies that vorticity is generated by the horizontal temperature gradient that causes its advection and diffusion. Here, $P r$ is the Prandtl number and $R a$ is the Rayleigh number; a superscript asterisk (*) is used to denote a dimensionless quantity. The continuity equation (Eq. (2)) is satisfied identically when the velocity components are expressed in terms of the gradient of the scalar stream function $\psi$ in which $u=\partial \psi / \partial y$ and $\mathrm{v}=-\partial \psi / \partial x$; this transformation, when applied to the vorticity component equation (Eq. (11)), yields Poisson's equation:

$$
\frac{\partial^{2} \psi^{*}}{\partial x^{* 2}}+\frac{\partial^{2} \psi^{*}}{\partial y^{* 2}}=-\xi^{*}
$$

which is used to solve for the flow field $(u, \mathrm{v})$. The flow field is generated by the buoyancy source term in the vorticity field equation from the diffusion of heat along the boundary of the enclosure communicated through the density field. The buoyancy source term is coupled to the temperature field given by its dimensionless form:

$$
\frac{\partial T^{*}}{\partial t^{*}}+\left(u^{*} \frac{\partial T^{*}}{\partial x^{*}}+\mathrm{v}^{*} \frac{\partial T^{*}}{\partial y^{*}}\right)=\left(\frac{\partial^{2} T^{*}}{\partial x^{* 2}}+\frac{\partial^{2} T^{*}}{\partial y^{* 2}}\right)
$$

obtained using the following temperature scale:

$$
T^{*}=\frac{T-T_{A}}{q^{\prime \prime} L / \kappa}
$$


In addition to $R a$ and $P r$ in the vorticity equation (Eq. (12)), which are defined as

$$
R a=\frac{\beta q^{\prime \prime} n \mathrm{~g}_{\mathrm{o}} L^{4}}{\kappa v \alpha} \quad \text { and } \quad \operatorname{Pr}=\frac{\nu}{\alpha}
$$

(where $v$ is the kinematic viscosity), the remaining parameters of the problem are obtained by nondimensionalizing the boundary conditions. This produces the heat flux ratios for the bottom and top boundaries, $f_{b}$ and $f_{t}$ :

$$
y^{*}=0, \quad \partial T^{*} /\left.\partial y^{*}\right|_{y^{*}=0}=-f_{b}
$$

and

$$
y^{*}=A r, \quad \partial T^{*} /\left.\partial y^{*}\right|_{y^{*}=A r}=-f_{t}
$$

and the heat flux ratios of the sidewall boundaries, $f_{s}$ :

$$
x^{*}=0, \quad \partial T^{*} /\left.\partial x^{*}\right|_{x^{*}=0}=-f_{s}
$$

and

$$
x^{*}=1, \quad \partial T^{*} /\left.\partial x^{*}\right|_{x^{*}=1}=-f_{s}
$$

An additional four parameters are obtained. These are the aspect ratio $A r$ and dimensionless heat fluxes $f_{b}$, $f_{t}$, and $f_{s}$ defined as

$$
\begin{gathered}
A r=\frac{H}{L} \\
f_{b}=\frac{q_{b}^{\prime \prime}}{q^{\prime \prime}} \\
f_{t}=\frac{q_{t}^{\prime \prime}}{q^{\prime \prime}} \\
f_{s}=\frac{q_{s}^{\prime \prime}}{q^{\prime \prime}}
\end{gathered}
$$

The heat flux scale $q^{\prime \prime}$ used in Equations (21b), (21c), and (21d) depends on the dominant prescribed heat flux at the enclosure boundary that causes convection. For this problem, it is the bottom heat flux $q_{b}^{\prime \prime}$ that drives convective instability since $q_{s}^{\prime \prime}<<q_{b}^{\prime \prime}$. In general, the parametric set $\Lambda$ consists of six parameters:

$$
\Lambda=\Lambda\left(R a, A r, \operatorname{Pr}, f_{s}, f_{b}, f_{t}\right)
$$

To simplify the parametric set, we consider a specific cryogenic fluid with fixed geometry such that $\mathrm{Pr}$ and $\mathrm{Ar}$ are constant. In addition, since we assume very low heat leakage at the sidewalls, $f_{s}$ is also 
constant. The heat load from the ambient environment affects $R a, f_{b}$, and $f_{t}$. Since $f_{b}=f_{t}$ and the use of the heat flux scale $q_{b}^{\prime \prime}$ implies that $f_{b}=1$ and $f_{t}=1$, variation of the heat flux appears in $f_{s}$. Thus, the reduced parametric set $\Lambda^{\prime}$ becomes

$$
\Lambda^{\prime}=\Lambda^{\prime}\left(R a, f_{s}\right)
$$

This implies that the effect of heat load from the ambient laboratory environment $\left(n g_{0}=1 g_{0}\right)$ on the temperature rise of liquid nitrogen inside an enclosure can be characterized by varying only two parameters: the Rayleigh number and the sidewall heat flux ratio. This simplification yields a reasonable set of parameters for computational parametric study.

To obtain a computational solution of the dynamical equations of motion for the reduced parametric set, we employ finite difference methods. First, we use a direct solver approach to solve Poisson's equation (Eq. (13)) using a matrix inversion that yields the flow field. The input of the flow field is used to solve for the temperature field in Equation (14) via a flux-corrected transport method used to resolve small-scale thermals. Finally, since the horizontal temperature gradient drives vorticity production through buoyancy, we solve the vorticity equation (Eq. (12)).

This direct solver approach requires the solution of Poisson's equation for the first time step only. Subsequent time steps use the vorticity field (Eq. (12)) as input to the temperature field to obtain a timemarching solution of the flow and temperature fields. Since we are interested in time-accurate solutions, we use a third-order Adams-Bashforth time-discretization scheme with a typical time step of approximately one-thousandth of a second: $\Delta t=0.00125 \mathrm{~s}$. Such a small time step allows an asymptotic solution of the flow field to be computed. Since we are considering relatively high Rayleigh numbers, $10^{9}$ to $10^{13}$, the smallest grid size employed is 1000 by 1000 . Owing to the large vertical height of the enclosure, asymptotic dynamics of the flow field require long-time computations, which can take on the order of 500 to $1000 \mathrm{hr}$ on a Silicon Graphics International Corporation (SGI) Altix supercomputer system. Memory requirements for each case range from a low of $12 \mathrm{CPU}$ to a midrange of $40 \mathrm{CPU}$ and a high of $100 \mathrm{CPU}$ on supercomputers with capacities of 508, 1024, and 2048 CPUs (1 CPU is approximately 2 GB). Thus, substantial computational resources are required to obtain solutions for the reduced parametric set.

\subsection{Numerical Results}

\subsection{Global Dynamics of the Flow Field for High Rayleigh Numbers}

Owing to the large geometric length scales of the enclosure $(L=19.1 \mathrm{~cm}$ and $H=61.9 \mathrm{~cm})$, computation at the lowest Rayleigh number, for the most conservative estimate of the heat load from the background laboratory environment, is on the order of $10^{9}$. For the range of Rayleigh numbers $\left(10^{9}\right.$ to $10^{13}$ ) considered to investigate the effect of background heat load $Q$ from 0.001 to $10 \mathrm{~W}$, we show that departure from thermodynamic equilibrium ensues from convective instability. The instability propagates from the bottom to the top of the enclosure and asymptotes to a traveling-wave-type motion of convective modes toward dynamical equilibrium. The global dynamics of the flow field indicate self-similarity of the flow as an asymptotic state is approached. However, the approach to the asymptotic state depends on the magnitude of the Rayleigh number.

For the most conservative estimate of background heat load $(Q=0.001 \mathrm{~W}$, which corresponds to $R a=10^{9}$ ), Figure 2 shows a typical base flow from which convective instability ensues. In response to heat load from the ambient, a heat flux of $q_{b}^{\prime \prime}=q_{t}^{\prime \prime}=3.49 \times 10^{1} \mathrm{erg} / \mathrm{cm}^{2}-\mathrm{s}$ is transmitted through the top and bottom surfaces, and careful insulation of the sidewalls allows for a minimal heat flux of $q_{s}^{\prime \prime}=0.001 \mathrm{erg} / \mathrm{cm}^{2}$-s. Throughout the parametric variation (the increase in background heat load), the absorption of heat flux through the sidewall is maintained constant at $q_{s}^{\prime \prime}=0.001 \mathrm{erg} / \mathrm{cm}^{2}-\mathrm{s}$. Figure 2 shows that prior to convective instability, the sidewall heat flux $f_{s}$ causes natural-convection-dominated base flow with two large counterrotating cells. This typical base flow exists for all Rayleigh numbers. The temperature field shows the conduction boundary layer $\delta$ built up at the top and bottom of the enclosure owing to heat flux $f_{t}$ and $f_{b}$. This 
is similar to the conduction sublayer in the phenomenological theory of Howard (Ref. 5) and the proto-sublayer of Elder (Ref. 8).

Figure 3 shows the transition by which the base flow field becomes unstable against convective instability. The instability of the thermal boundary layer thickness $\delta$ is evident at $t=300 \mathrm{~s}$ and shows that the disturbance remains embedded in the proto-sublayer as pointed out by Elder (Ref. 8). Due to the fact that heat flux is absorbed at the top and bottom of the enclosure, convective instability unfolds at the bottom of the enclosure owing to an adverse temperature gradient stemming from the unstable density gradient driven by buoyancy, while the top of the enclosure is convectively stable since the density gradient is stably stratified. These results are in agreement with the findings of Townsend (Ref. 4) and Elder (Ref. 8) that convective motion at early times is dependent on the thermal boundary layer thickness and is independent of the height of the enclosure. As shown in Figure 3, the six cells that are generated initially are segregated (at $t$ $=300 \mathrm{~s}$ ) toward the bottom wall corner, similar to the findings of Elder (Ref. 7). The growth of these cells yields small-scale thermals (at $t=432 \mathrm{~s}$ ) (as shown by the temperature field) while the six cells self-organize into two larger cells with small secondary cells (as shown by the flow field). The amalgamation of the cells indicates a local increase in the wavelengths of the cells as also observed by Elder (Ref. 7). According to Elder (Ref. 8), the amalgamation of cells was also observed in laboratory experiments and represents a broadening of the spatial spectrum of the velocity field to lower wavenumbers or higher wavelengths.

The transition from short-time-scale events, in which thermals break off, to long-time-scale events, which mark the propagation of the instability, occurs for $t>432 \mathrm{~s}$. The shear instability of the top convective cell, with the quiescent fluid on top, forms a local source that excites the growth of secondary vortices $(t=432 \mathrm{~s})$. Self-repetition of the internal shear instability mechanism leads to the propagation of the local convective instability front toward the top of the enclosure $(t=1728 \mathrm{~s})$. As the top of the enclosure is approached, this system of four symmetric counterrotating vortices becomes asymmetric, and the breakdown of symmetry in the system is shown for $t=1872 \mathrm{~s}$. Regions of shear instability between the four cells bifurcate to a series of secondary cells, which leads to self-organization of the flow field into a set of four asymmetric cells. These cells are precursors to a traveling-wave-type motion of convective modes. The traveling-wave-type mode occurs after the computation time of $1872 \mathrm{~s}$. However, as will be shown, increasing the background heat load $Q$ to $0.01 \mathrm{~W}$ or $R a$ to $10^{10}$ increases the speed at which the instability propagates toward the top of the enclosure. Note that in Figure 3, and in the following figures, the local coordinates, $x_{p}$ and $y_{p}$, are used for graphics which are normalized, for convenience, with respect to $L$ and $H$, respectively. However, the normal dimensionless coordinates, $x^{*}$ and $y^{*}$, which bound the internal region of the enclosure, are normalized with respect to the horizontal length scale $L$.

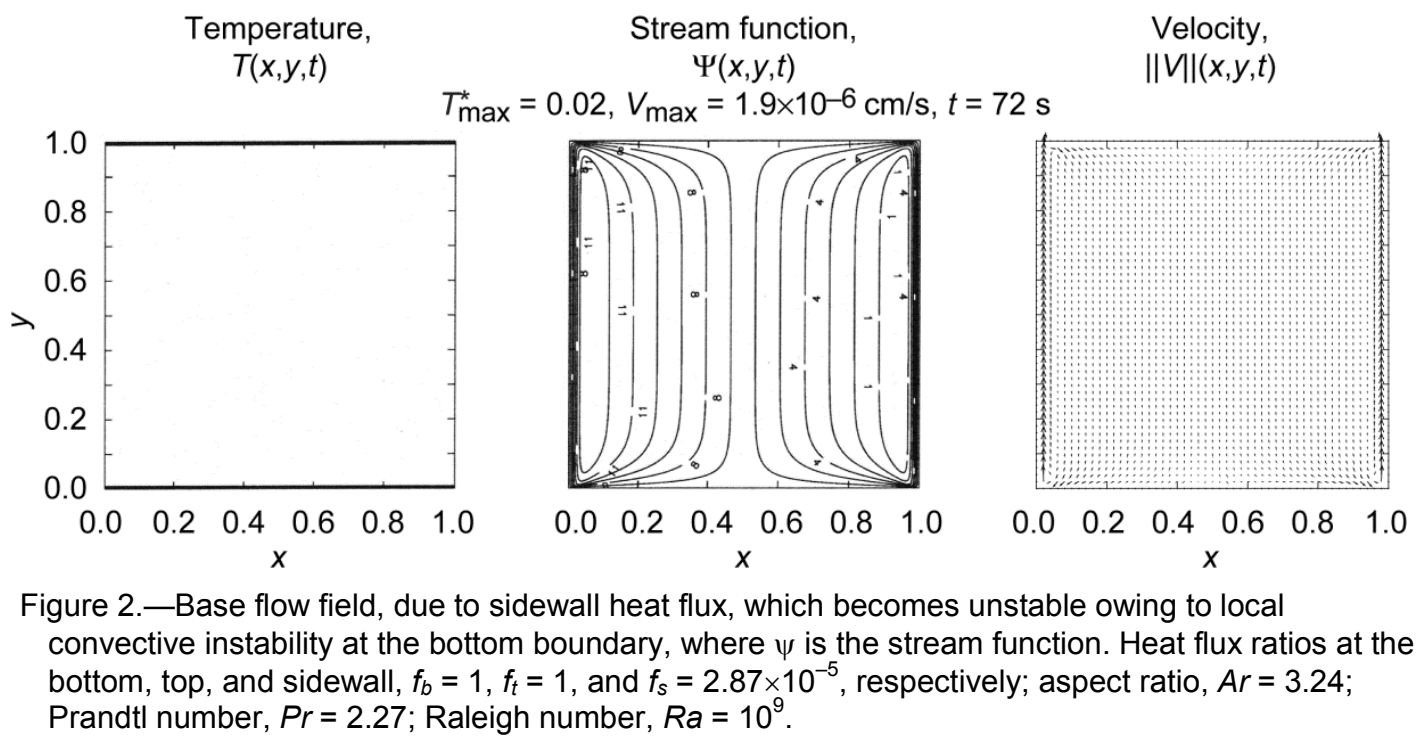




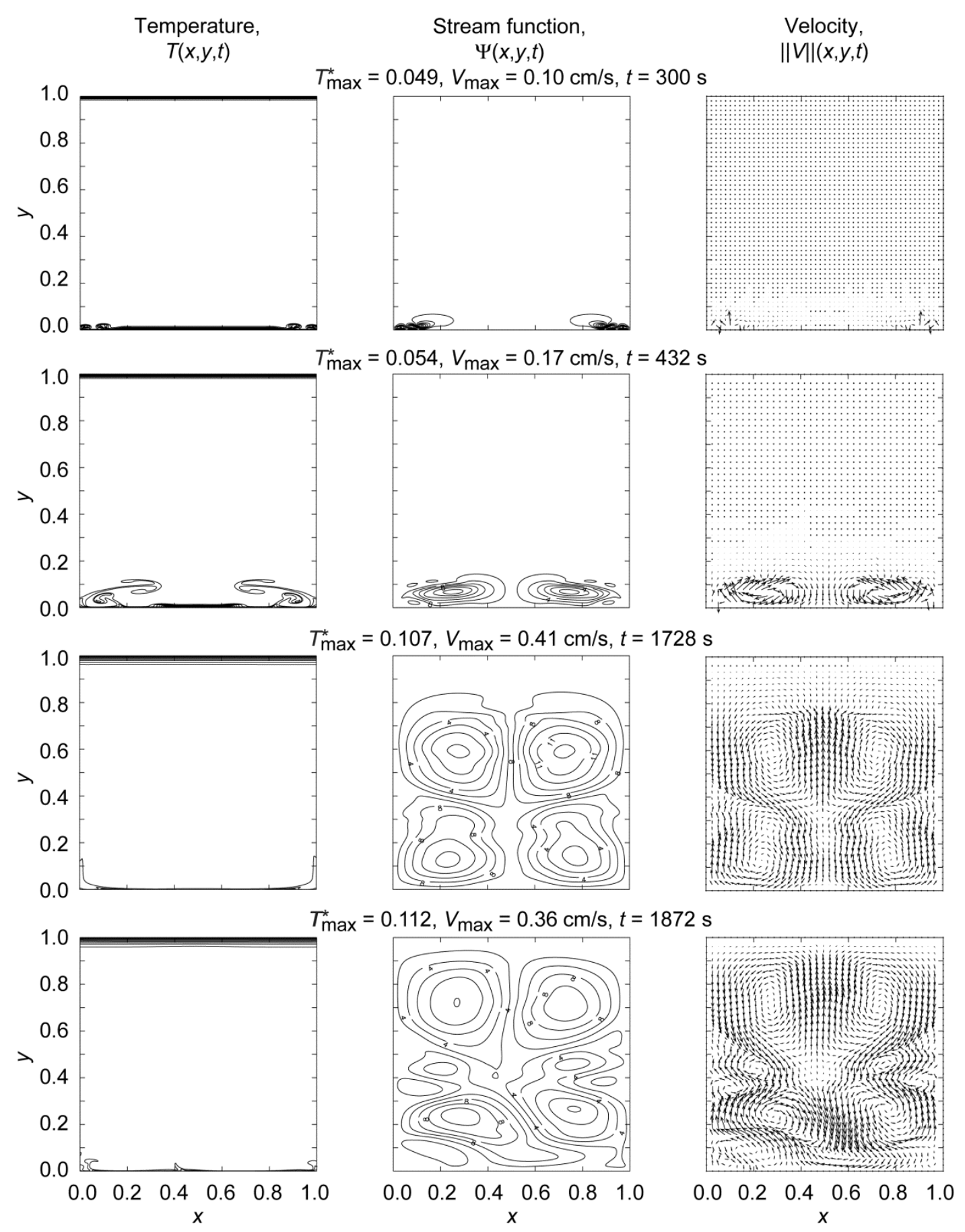

Figure 3.-Global dynamics of the flow field, showing the growth of thermals over time, $t$, and the propagation of the flow field leading to incipient asymmetry; heat fluxes at the sidewall, bottom, and top, $q_{s}^{\prime \prime}=0.001 \mathrm{erg} / \mathrm{cm}^{2}-\mathrm{s}$ and $q_{b}^{\prime \prime}=q_{t}^{\prime \prime}=3.49 \times 10^{1} \mathrm{erg} / \mathrm{cm}^{2}-\mathrm{s}$, respectively; heat flux ratios at the bottom, top, and sidewalls, $f_{b}=1, f_{t}=1$, and $f_{s}=2.87 \times 10^{-5}$, respectively; heat load, $Q=0.001$ W; aspect ratio, $A r=3.24$ (height and width of enclosure, $H=61.9 \mathrm{~cm}$ and $L=19.1 \mathrm{~cm}$ ); Prandtl number, $\operatorname{Pr}=2.27$; and Raleigh number, $R a=10^{9}$. Results are shown for increasing time. 


\subsection{Traveling-Wave-Type Mode}

The effect of increasing the absorption of heat on the boundary of the enclosure from the ambient environment is to increase the speed of transition to a traveling-wave-type motion of convective modes. For the same time scale as in Figure $3(t=1872 \mathrm{~s})$, Figure 4 shows for $R a=10^{10}$ the propagation of the basic four symmetric modes $(t=432 \mathrm{~s})$ and their breakdown to asymmetric modes $(t=576 \mathrm{~s})$, which leads to the traveling-wave-type motion of convective modes ( $t=864$ to $1872 \mathrm{~s})$. Unlike for $R a=10^{9}$, the transition to asymmetric modes $(t=576 \mathrm{~s})$ occurs before the instability front reaches the top of the enclosure. The asymmetric front $t=576 \mathrm{~s}(t<792 \mathrm{~s})$ propagates toward the top of the enclosure through shear instability, which generates secondary modes until the top of the enclosure is reached $(t=792 \mathrm{~s})$ and a fourth mode emerges. The fourth mode is a precursor to a traveling-wave-type mode $(t=864 \mathrm{~s})$ that propagates between the top and bottom of the enclosure as time increases. As shown by the vorticity field in Figure 4, the dynamics of this traveling-wave-type mode generates internal vorticity that mixes the liquid. Consequently, the temperature is uniform along the height of the enclosure even though, as will be shown, the flow and temperature fields are oscillating in time locally $(t=1872 \mathrm{~s})$.

The characteristic observation time for the laboratory experiments for the case of no heater and no screen (Ref. 1) is $t=600 \mathrm{~s}$. Figure 5 shows the characteristics of the flow and vorticity fields for a time scale of $720 \mathrm{~s}$ in order to gauge typical convective events. Dynamical events in Figure 5 are shown as a function of increasing heat absorption $Q$ from 0.001 to $1.0 \mathrm{~W}$, corresponding to increasing $R a$ from $10^{9}$ to $10^{12}$. The effect of increasing the background heat load $Q$ is to increase the speed at which the instability propagates toward the top of the enclosure and its transition to a traveling-wave-type mode. Figure 5 shows that the shear instability between the asymmetric modes generates the production of internal vorticity in which the intensity increases with increasing Rayleigh number. As $R a$ increases from $10^{10}$ to $10^{12}$, the slight decrease in the maximum temperature near the top of the enclosure is evidence of the effectiveness of mixing due to the intense production of vorticity. On the other hand, there is a fast increase in the maximum velocity - from 0.83 to $7.48 \mathrm{~cm} / \mathrm{s}$. Even though the background heat load from the experiment (Ref. 1) is unknown, Figure 5 gives an indication of the effect of a range of heat-load conditions on convective instability. For $R a=10^{9}$ and $Q=0.001 \mathrm{~W}$, the instability penetrates only about 20 percent of the height of the enclosure over the time scale of the experiment. Thus, it is unlikely that a heat load of $Q=0.001 \mathrm{~W}$ would be absorbed. The temperature measurements from the experiments indicate that convective instability has penetrated the entire height of the enclosure, implying that $Q \geq 0.1 \mathrm{~W}$. Even though the depth of penetration of the instability helps to establish a lower bound on the heat absorption, it is the magnitude of the increase in temperature with time that dictates the neighborhood of the heat-load absorption. This will be shown by probing the flow field at various fixed points $\left(x_{p}, y_{p}\right)$.

\subsection{Small-Scale Flows}

As the background heat load increases beyond $Q=0.01 \mathrm{~W}\left(R a=10^{10}\right)$, it becomes challenging to obtain computational solutions owing to the increase in mode numbers, which characterizes the onset of convective instability. Figure 6 shows the bifurcation to higher mode numbers for increasing heat load or Rayleigh number. The first bifurcation - from six to eight modes - occurs for $R a=10^{11}$, which is characterized by intensive vorticity production near the bottom boundary. The second bifurcation-from 8 to 10 modes - occurs for a decade increase in Rayleigh number, $R a=10^{12}$, or heat load, $Q=1 \mathrm{~W}$. After another decade increase in Rayleigh number, $R a=10^{13}$, the mode numbers double to approximately 20 modes. This explosive increase in mode numbers required an increase in grid size to 1500 by 1500 for small-scale resolution. The explosive increase in mode numbers caused a considerable challenge in obtaining computational solutions of time-asymptotic dynamical states for $R a=10^{13}$. Small-scale thermals erupt from the bottom wall on the same time scale as the growth of the instability; this is shown for $R a=10^{13}$ and $10^{11}$ in Figure 6. 

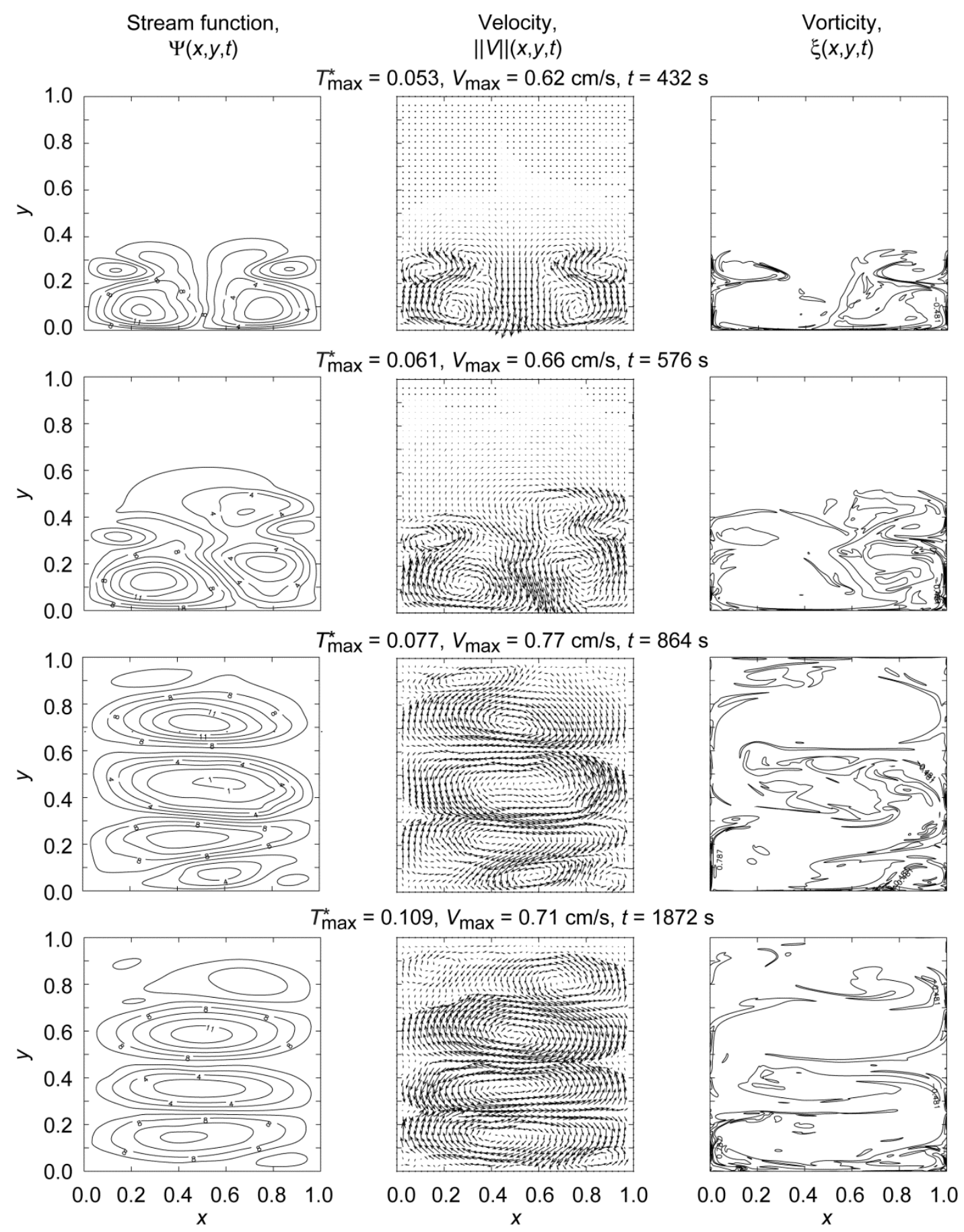

Figure 4.-Transition to asymmetry leading to the traveling-wave-type motion of convective modes; heat fluxes at the sidewall, bottom, and top, $q_{s}^{\prime \prime}=0.001 \mathrm{erg} / \mathrm{cm}^{2}-\mathrm{s}$ and $q_{b}^{\prime \prime}=q_{t}^{\prime \prime}=3.49 \times 10^{2} \mathrm{erg} / \mathrm{cm}^{2}-\mathrm{s}$, respectively; heat flux ratios at the bottom, top, and sidewalls, $f_{b}=1, f_{t}=1, f_{s}=2.87 \times 10^{-6}$, respectively; heat load, $Q=0.01 \mathrm{~W}$; aspect ratio, $A r=3.24$ (height and width of enclosure, $H=61.9 \mathrm{~cm}$ and $L=19.1 \mathrm{~cm}$ ); PrandtI number, $\operatorname{Pr}=2.27$; and Rayleigh number, $R a=10^{10}$. Results are shown for increasing times, $t$. 


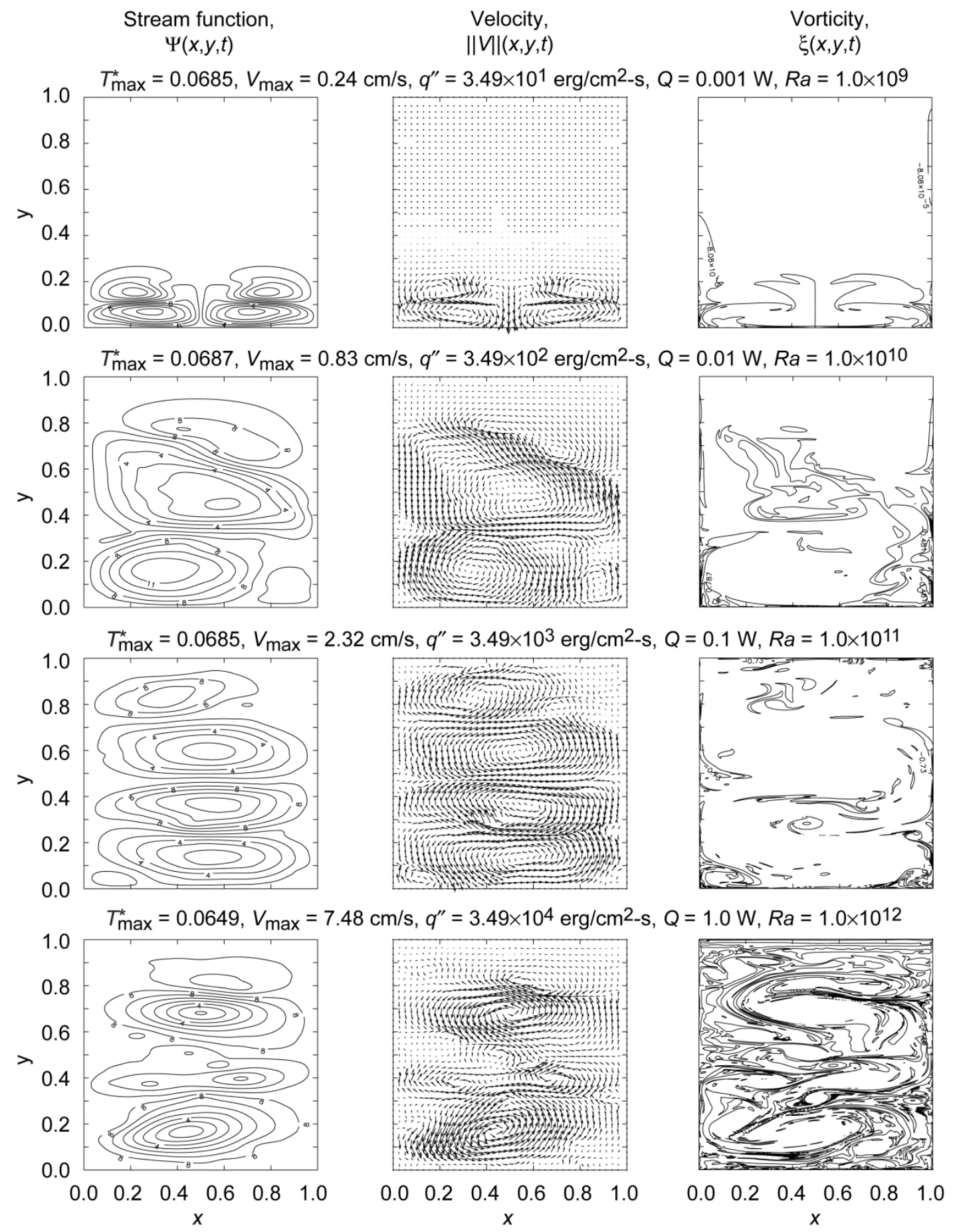

Figure 5.-Effect of heat flux absorption at the sidewall, bottom, and top $\left(q_{s}^{\prime \prime}=0.001 \mathrm{erg} / \mathrm{cm}^{2}\right.$-s and $q^{\prime \prime}=q_{b}^{\prime \prime}=q_{t}^{\prime \prime}$, respectively) on vorticity production over a time scale of $t=720 \mathrm{~s}$. Heat flux ratios $f_{b}=1, f_{t}=1, f_{s}=2.87 \times 10^{-5}$ to $2.87 \times 10^{-8}$ (corresponding to heat loads of $Q=0.001$ to $1.0 \mathrm{~W}$ ); aspect ratio, $A r=3.24$ (height and width of enclosure, $H=61.9 \mathrm{~cm}$ and $L=19.1 \mathrm{~cm}$ ); and Prandtl number, $\operatorname{Pr}=2.27$. Results are shown for increasing heat flux absorptions, $q^{\prime \prime}$; heat loads, $Q$; and Rayleigh numbers, $R a$. 


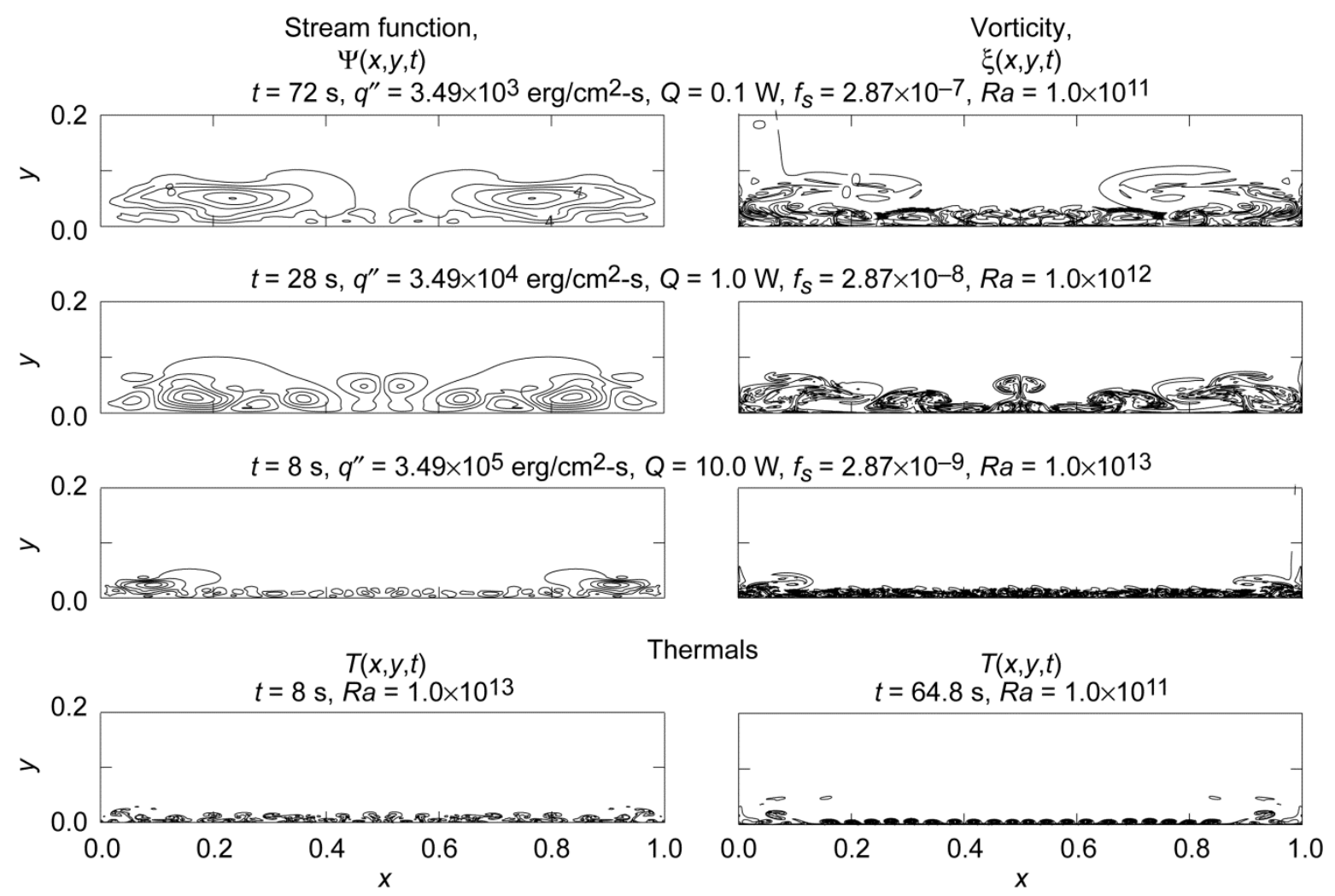

Figure 6.-Bifurcation to higher mode numbers for increasing Rayleigh numbers (grid size increases from 1000 by 1000 to 1500 by 1500 for Rayleigh number, $R a=10^{13}$ ) and small-scale thermals. Aspect ratio, $A r=3.24$; and Prandtl number, $\operatorname{Pr}=2.27$. Results are shown for different times, $t$; heat fluxes, $q "$; heat loads, $Q$; heat flux ratios at sidewalls, $f_{s}$; and Rayleigh numbers, $R a$.

Since the resolution of small scales becomes important for the highest Rayleigh number, $R a=10^{13}$, or heat load, $Q=10 \mathrm{~W}$, considered, we show in Figure 7 the effect of grid size, which illustrates sensitivity to initial conditions. At $R a=10^{13}$, the system is highly nonlinear and, as will be shown, becomes chaotic for $R a<10^{13}$. A chaotic dynamical system implies sensitivity to initial conditions. For a time scale of $t=9 \mathrm{~s}$, the increase in grid numbers from 1000 by 1000 to 2500 by 2500 serves as a test for sensitivity to initial conditions. The increase in grid numbers represents a perturbation to the base flow solution and shows slight nuances in the dynamics of the modes; however, a grid size of 2000 by 2000 is adequate to resolve the short-time-scale dynamics of the growth of modes. The difference between 2000 by 2000 and 2500 by 2500 is due to the fact that the dynamics of mode interactions is also sensitive to the grid number density. In addition, self-organization of the modes occurs rapidly, which can result in slight nuances in mode numbers. This implies that a pattern similar to that for the 2000 by 2000 grid occurs for a 2500 by 2500 grid, but at $t<9 \mathrm{~s}$. Because of this sensitivity to the initial condition, the exact patterns are not be repeated at fixed time $t=9 \mathrm{~s}$ as the grid size increases. However, certain basic patterns remain the same: that is, the explosion to higher mode numbers and the increase in vorticity production near the bottom wall.

Figure 8 shows the self-similarity of the propagation of the convective instability for a 2000 by 2000 grid at $R a=10^{13}$, which corresponds to the upper bound in heat load. This figure illustrates that, beyond the onset of convective instability at $t=8 \mathrm{~s}$, in which there is an explosion in mode numbers, the growth of the instability, $9.6 \mathrm{~s} \leq t \leq 19.2 \mathrm{~s}$, occurs through the self-organization of modes, which results in the basic four symmetric counterrotating vortices that also occur for the lowest Rayleigh number $\left(\operatorname{Ra}=10^{9}\right)$. Beyond $t>19.2 \mathrm{~s}$, this convective state follows trends similar to those shown for the lower Rayleigh numbers: that is, transition to asymmetry leading to a traveling-wave-type mode. As the flow propagates upwards, there is an increase in the small-scale internal production of vorticity in the bulk flow field. 

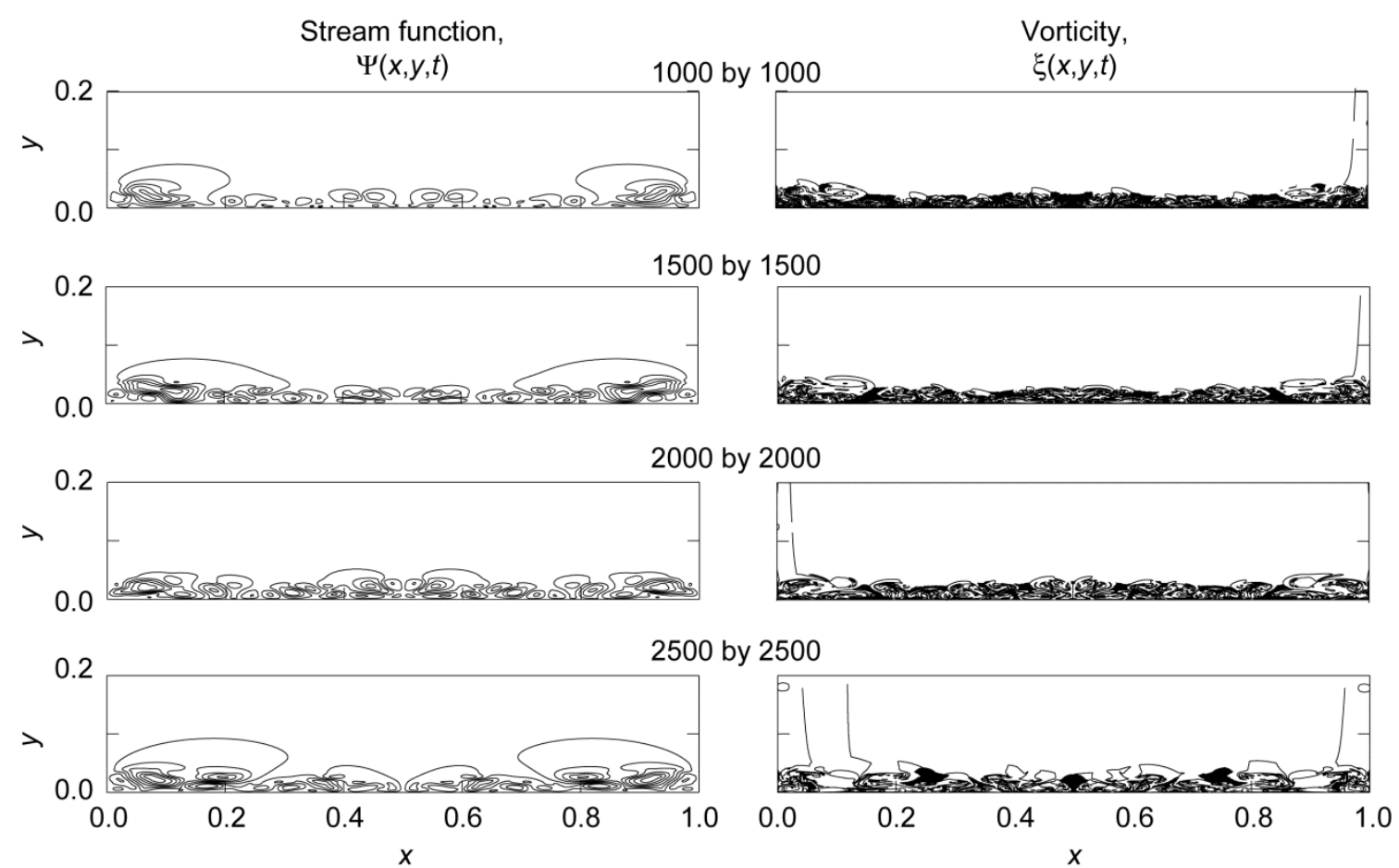

Figure 7.- Illustration of sensitivity to initial conditions showing the effect of grid size on the resolution of small scales at time, $t=9.0 \mathrm{~s}$, for Rayleigh number, $R a=10^{13}$; heat flux, $q^{\prime \prime}=3.49 \times 10^{5} \mathrm{erg} / \mathrm{cm}^{2}-\mathrm{s}$; heat load, $Q=10.0 \mathrm{~W}$; heat flux ratios at the bottom, top, and sidewall, $f_{b}=1, f_{t}=1, f_{s}=2.87 \times 10^{-9}$, respectively; aspect ratio, $A r=3.24$; and Prandtl number, $\operatorname{Pr}=2.27$.

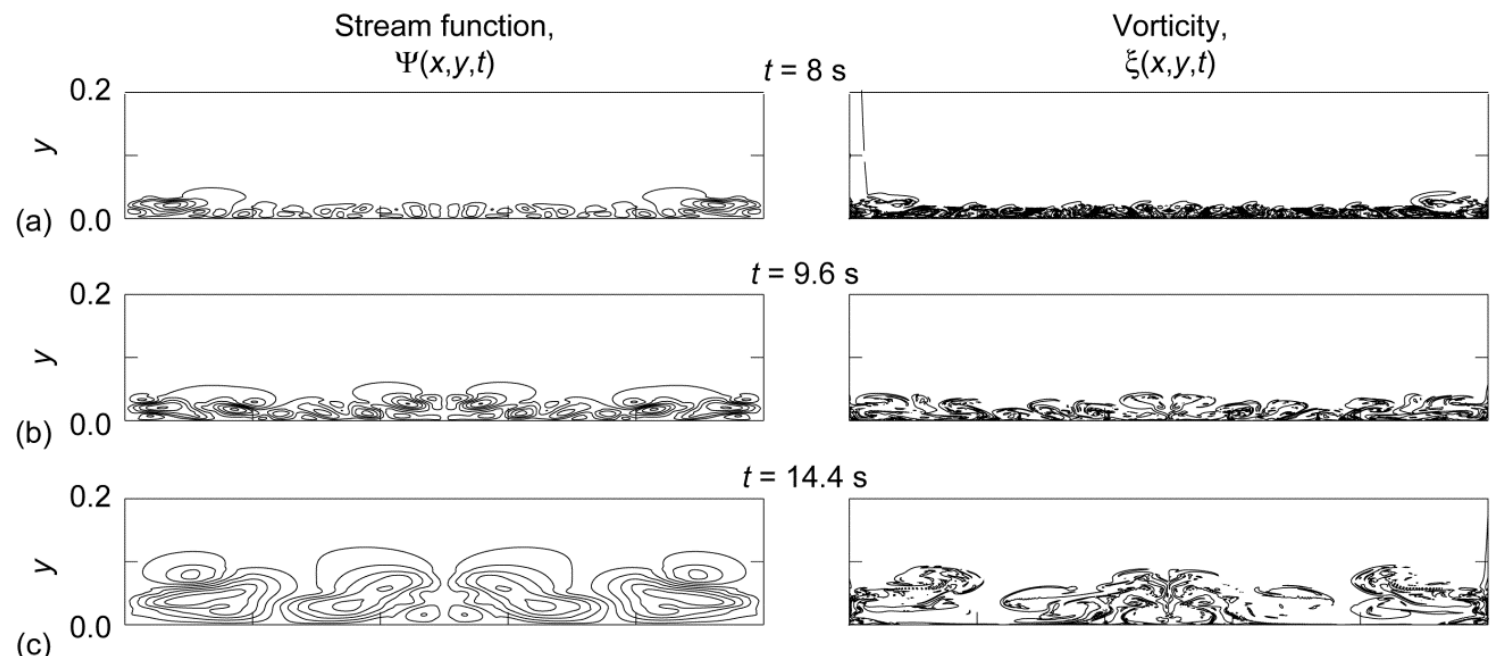

(c)

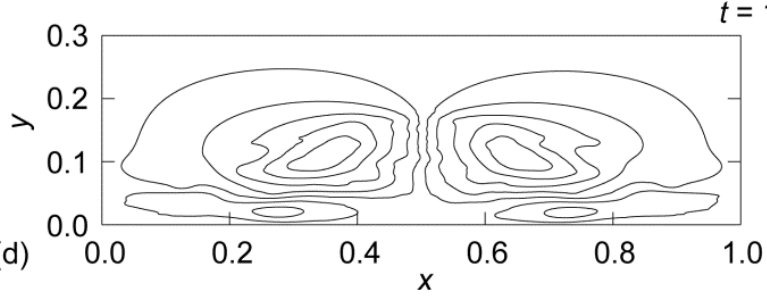

$t=19.2 \mathrm{~s}$

Figure 8.-Evolution of instability at small scales, showing the self-organization of modes and vorticity production as the instability propagates from time, $t$, of $8 \mathrm{~s}$ to $19.2 \mathrm{~s}$. Heat flux, $q^{\prime \prime}=3.49 \times 10^{5} \mathrm{erg} / \mathrm{cm}^{2}-\mathrm{s}$; heat load, $Q=10.0 \mathrm{~W}$; aspect ratio, $A r=3.24$; Prandtl number, $\operatorname{Pr}=2.27$; Rayleigh number, $\operatorname{Ra}=10^{13}$; and grid size, 2000 by 2000. 


\subsection{Scalar Measures}

For the time scale of the experiments (Ref. 1), Figures 9(a) and (b) show the characteristic maximum velocity and temperature due to heat absorption from the ambient background environment. There is a sharp increase in the maximum velocity as the heat absorption or the Rayleigh number increases (Fig. 9(a)). The fast increase in velocity is the cause for the decrease in time scale for the propagation of the convective instability along the height of the enclosure. An increase in the heat absorption from the environment causes a rise in the maximum temperature at the top boundary (Fig. 9(b)). For a short time ( $t=360 \mathrm{~s})$, the maximum temperature remains nearly constant, and for a long time $(t=720 \mathrm{~s})$, the maximum temperature decreases as the Rayleigh number increases due to the fact that intensive convective motion mixes the fluid in the top boundary layer near the wall.
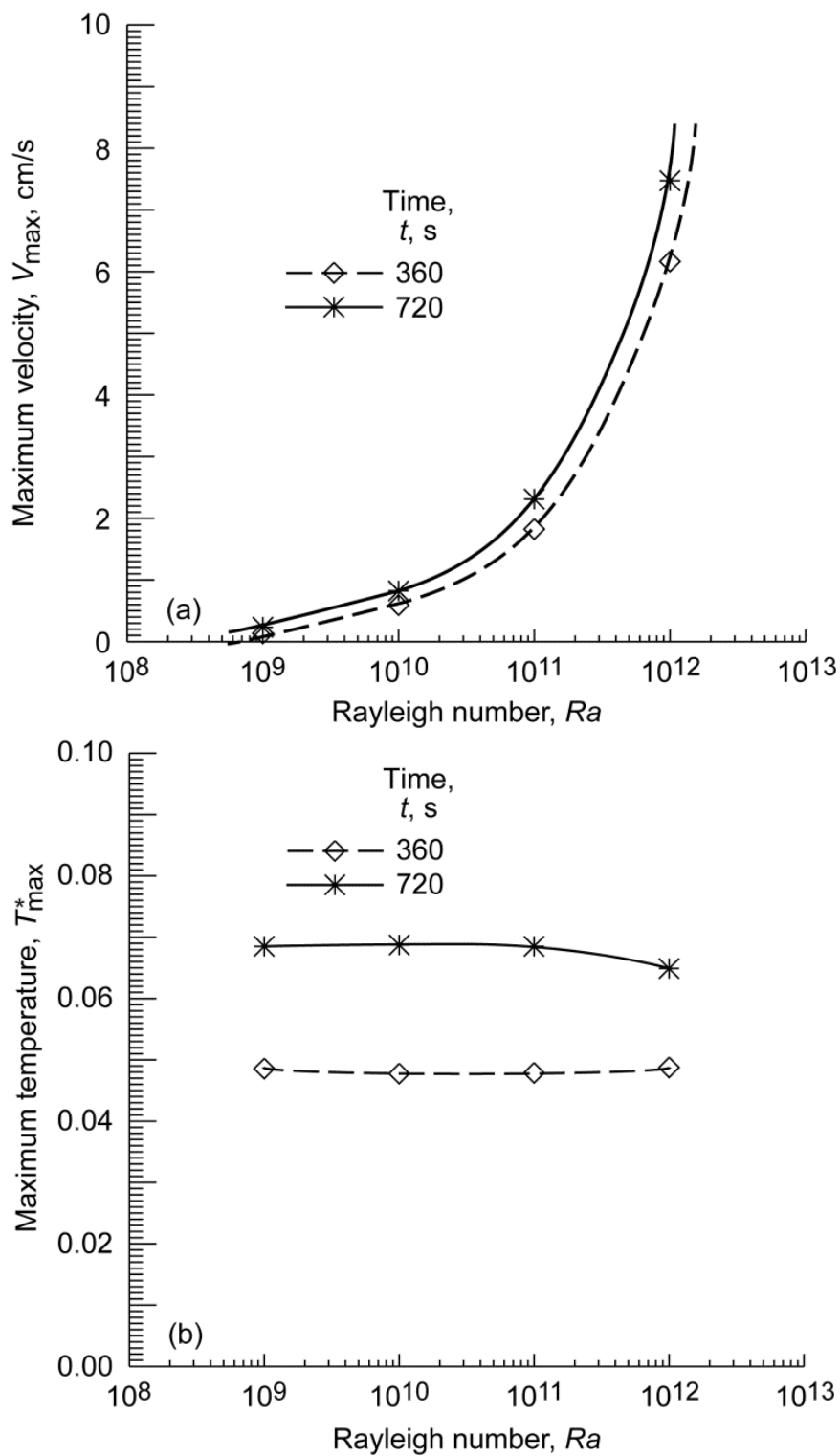

Figure 9.-Maximum velocity $\left(V_{\max }\right)$ and temperature $\left(T_{\max }\right)$ as a function of Rayleigh number, $R a$. Aspect ratio, $A r=3.24$; Prandtl number, $\operatorname{Pr}=2.27$; heat flux ratios at the bottom and top, $f_{b}=1$ and $f_{t}=1$, respectively. (a) Maximum velocity in flow field as heat absorption from the ambient environment increases for a fixed time. (b) Effect of heat absorption from the ambient environment on maximum temperature inside the enclosure for a fixed time. 


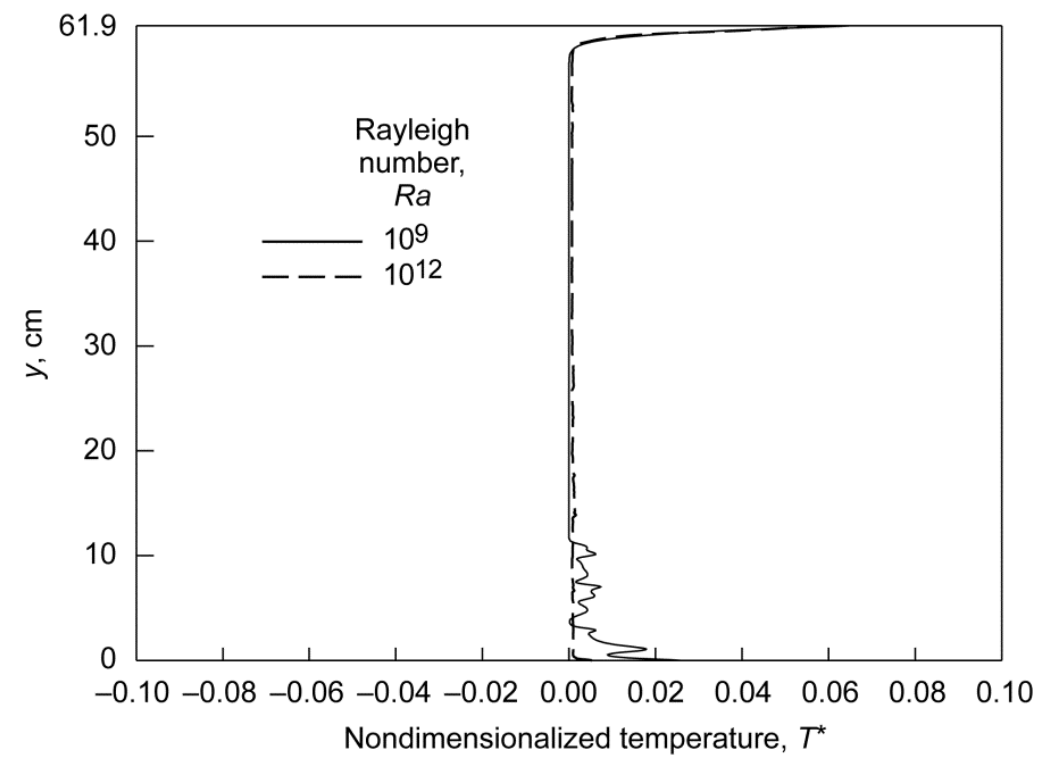

Figure 10.-Temperature profile along the vertical axis at $x_{p}=2.87 \mathrm{~cm}$ and fixed time $t=648 \mathrm{~s}$ for increasing Rayleigh numbers at ambient conditions for two heat loads: heat flux ratios at the sidewall, $f_{s}=2.87 \times 10^{-5}$ (heat flux, $q^{\prime \prime}=3.48 \times 10^{1} \mathrm{erg} / \mathrm{cm}^{2}-\mathrm{s}$; heat load, $Q=0.001 \mathrm{~W}$ ) and $f_{s}=2.87 \times 10^{-8}$ $\left(q "=3.49 \times 10^{4} \mathrm{erg} / \mathrm{cm}^{2}-\mathrm{s}, Q=1.0 \mathrm{~W}\right)$. Aspect ratio, $A r=3.24$; Prandtl number, $\operatorname{Pr}=2.27$; and heat flux ratio at the bottom and top, $f_{b}=1$ and $f_{t}=1$, respectively.

The temperature profile along the vertical axis is contrasted for low $Q=0.001 \mathrm{~W}\left(R a=10^{9}\right)$ to moderate $Q=1 \mathrm{~W}\left(R a=10^{12}\right)$ heat absorption in Figure 10. Over the time scale of the experiment (Ref. 1) $(\mathrm{t}=600 \mathrm{~s})$, the propagation of convective instability penetrates about 20 percent of the height of the enclosure for $Q=0.001 \mathrm{~W}$, whereas the instability propagates the entire height of the enclosure for $Q=1 \mathrm{~W}$. For $R a=10^{12}$, the temperature remains nearly constant throughout the bulk of the liquid, with a large temperature gradient in the stably stratified layer near the top wall and a well mixed layer near the bottom wall.

\subsection{Local Dynamics at Fixed Points}

The response of the temperature and flow fields at a fixed point $\left(x_{p}^{*}=0.15, y_{p}^{*}=0.1\right)$ near the bottom of the enclosure for long $\left(R a=10^{9}\right.$ to $\left.10^{12}\right)$ and short $\left(R a=10^{13}\right)$ time bands for various heat loads from the ambient laboratory environment is shown in Figure 11. These predictions indicate the response time for the onset of convective instability as the Rayleigh number or heat absorption increases. The response time of the instability at 10 percent of the enclosure height decreases from $t=400 \mathrm{~s}$ for $R a=10^{9}$ to $t=15 \mathrm{~s}$ for $R a=10^{13}$ as more heat is absorbed from the environment. Both the temperature and velocity fields oscillate aperiodically from $R a=10^{9}$ to $10^{13}$, this is due in part to the large dimensions of the enclosure, $A r=3.24$ $(H=61.9 \mathrm{~cm}$ and $L=19.1 \mathrm{~cm})$. The velocity and temperature fluctuations increase as the heat load or Rayleigh number increase. The time series for the velocity field component is nearly stationary in the mean, varies about a fixed level for $R a=10^{9}$, and varies slightly about the mean for a segment of the time series for $R a=10^{10}$ and $10^{11}$. However, for $R a=10^{12}$ to $10^{13}$, the velocity field is nonstationary in the mean, does not vary about a mean fixed level, and has an upward trend. This implies that the mean varies with time for high Rayleigh numbers. An estimation of an average value from such a time series should take into account the variation of the mean with time. On the other hand, the temperature field is stationary for $R a=10^{9}$ to $10^{10}$, and a nonstationary time series occurs for $R a=10^{11}$ and $10^{12}$ for $t>200 \mathrm{~s}$, which started out as stationary for the short time band $t<200 \mathrm{~s}$. Since we show only a short time band of the time series for $R a=10^{13}$, stationary behavior appears; however, a nonstationary trend would ensue for a time band on the order of $800 \mathrm{~s}$, similar to $R a=10^{12}$. These trends indicate that the averaging of temperatures for various points on a plane should take into account the nonstationary behavior of the time series so that the temperature histories can be correlated properly with the convective states of the flow field. 

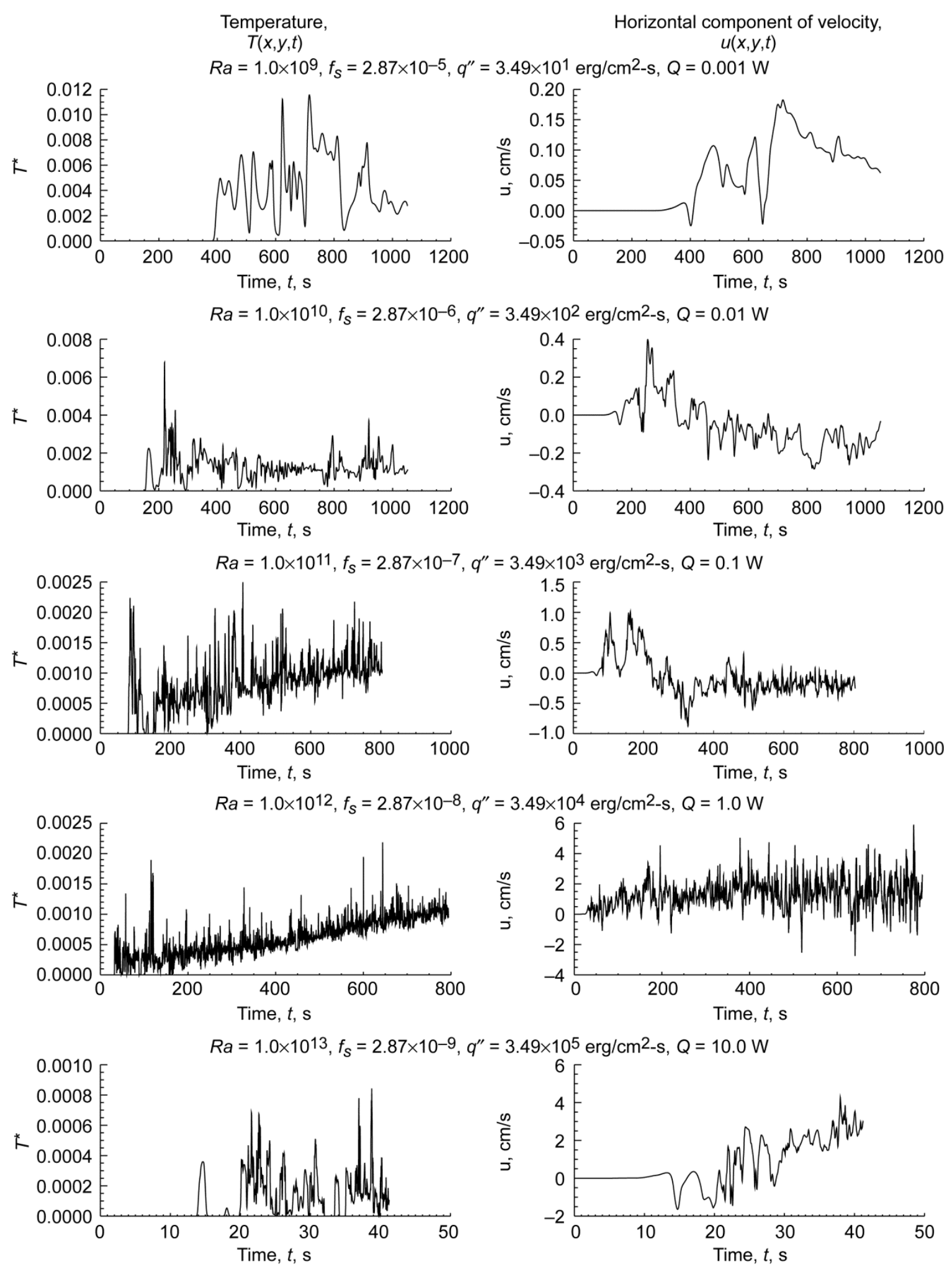

Figure 11.-Time history of nondimensional temperature, $T^{*}$, and velocity fields (horizontal component of velocity, $u)$ near the bottom of the enclosure $\left(x_{p}^{*}=0.15, y_{p}^{*}=0.1\right)$, showing an increase in intensity of the fluctuations as the Rayleigh number, $\mathrm{Ra}$ (heat absorption) increases for aspect ratio, $\mathrm{Ar}=3.24$ (height and length of enclosure, $H=69.1 \mathrm{~cm}$ and $L=19.1 \mathrm{~cm}$ ); Prandtl number, $\operatorname{Pr}=2.27$; and heat flux ratios at bottom and top of enclosure, $f_{b}=1$ and $f_{t}=1$, respectively. Results are shown for different heat flux ratios at the side wall, $f_{s}$, heat fluxes, $q^{\prime \prime}$, heat loads, $Q$, and Rayleigh numbers, $R a$. 
Since the temperature at fixed points $\left(x_{p}, y_{p}\right)$ was measured experimentally along the height of the enclosure (Ref. 1), Figure 12 provides the time history of the temperature field for various points along the enclosure height, contrasting low $(Q=0.01 \mathrm{~W})$ and moderate $(Q=1.0 \mathrm{~W})$ heat absorption. The experimental temperature measurements (Ref. 1) reported were averaged values over a plane consisting of five points at each $y_{p}^{*}$ location - near $0.1,0.35,0.65$, and 0.90 - over a time span of $t=600 \mathrm{~s}$. Figure 12 shows boundary layer locations at $y_{p}^{*}=0.001$ and 0.999 near the bottom and top wall boundaries to illustrate the instantaneous response of the fluid so that it can be compared with experimental trends. For $R a=10^{10}$, in response to heat absorption at the bottom boundary $\left(y_{p}^{*}=0.001\right)$, there is a sharp rise in temperature over a time scale of $t=100 \mathrm{~s}$, and the onset of oscillations follows for $t>100 \mathrm{~s}$. As the convective instability propagates toward the top of the enclosure, there is a delay time $\tau_{D}$ for the onset of convective instability: for $y_{p}^{*}=0.1, \tau_{D}=150 \mathrm{~s}$; whereas for $y_{p}^{*}=0.9, \tau_{D}=750 \mathrm{~s}$.

Similar to results for the bottom boundary, heat absorption at the top boundary increases the local temperature; however, owing to the stably stratified layer on top $\left(y_{p}^{*}=0.999\right)$, the temperature continues to rise steadily past $t=100 \mathrm{~s}$ up to $t=800 \mathrm{~s}$, beyond which the onset of convective instability begins. Based on the delay time of $\tau_{D}=800 \mathrm{~s}$ for convective instability to propagate the entire length of the enclosure, a heat load of $Q=0.01 \mathrm{~W}$ is not sufficient. For $R a=10^{10}(Q=0.01 \mathrm{~W})$, the delay time of $\tau_{D}=750 \mathrm{~s}$ at $y_{p}^{*}=0.9$ is too long for the propagation of convective instability in comparison to the experimental (Ref. 1) measurement time band of $t=600 \mathrm{~s}$. This implies that the instability would not have reached the top of the enclosure. Thus, a background heat load of $Q=0.01 \mathrm{~W}$ is too small. However, a decade increase to $R a=10^{11}(Q=0.1 \mathrm{~W})$ indicates a delay time of $\tau_{D}=400 \mathrm{~s}$ at $y_{p}^{*}=0.9$, which falls within the experimentally measured time band of $t=600 \mathrm{~s}$. Thus, $R a=10^{11}(Q=0.1 \mathrm{~W})$ can potentially serve as a lower bound for heat absorption from the ambient laboratory environment. However, when temperature magnitudes are compared with experimental values for $R a=10^{11}$, they fall below the experimental measurements (Ref. 1). Another decade increase in heat load to $Q=1.0 \mathrm{~W}, R a=10^{12}$, shows a gradual approach to reported experimental values of average temperature and serves as a lower bound for heat absorption from the ambient environment.

The dynamics of the temperature field at fixed points $\left(x_{p}, y_{p}\right)$ spanning the height of the enclosure in Figure 12, shows a decrease in the penetrative convection response time as the Rayleigh number increases. In comparison to $R a=10^{10}$, the delay response time of penetrative convective instability is reduced for $R a=10^{12}$ as the height increases. The response time ranges from $\tau_{D}=25$ to $155 \mathrm{~s}$, corresponding to $y_{p}^{*}=0.1$ and 0.9 , respectively. As the probing distance $\left(y_{p}^{*}\right)$ increases from the bottom, the signal varies from a stationary time series about a constant mean value $\left(y_{p}^{*}=0.001\right)$ to a nonstationary time series about a mean value that increases with time $\left(y_{p}^{*}=0.1\right)$. This trend is maintained as the enclosure height is traversed to the top boundary $\left(y_{p}^{*}=0.9\right)$, which indicates intermittency. In addition, the convective instability penetrates the top boundary layer at $y_{p}^{*}=0.999$, showing intermittency through periodic bursts of intensive convective motion. Owing to the lag in response time $\tau_{D}$ associated with locations from $y_{p}^{*}=0.1$ to $0.9\left(\tau_{D}=25\right.$ to $\left.155 \mathrm{~s}\right)$, a comparison with experiments over the short time scale of $t=60 \mathrm{~s}$ is inadequate for $y_{p}^{*}>0.3$ since the experimental measurements indicate nearly instantaneous rise in temperature as shown at $y_{p}^{*}=0.001$ and 0.999 . However, for a time band of $t \geq 200 \mathrm{~s}$, adequate comparisons can be made with experimental data.

The computational model accounts for the response of the temperature field to a step input of heat absorption from the boundaries and represents a clearly posed initial value problem. However, there exists uncertainty associated with the initial condition of an experimental system. Since heat is absorbed instantaneously, the origin of time $(t=0)$ may be uncertain, considering the complexity of temperature measurements and the establishment of the initial saturation condition for liquid nitrogen. Considering the 

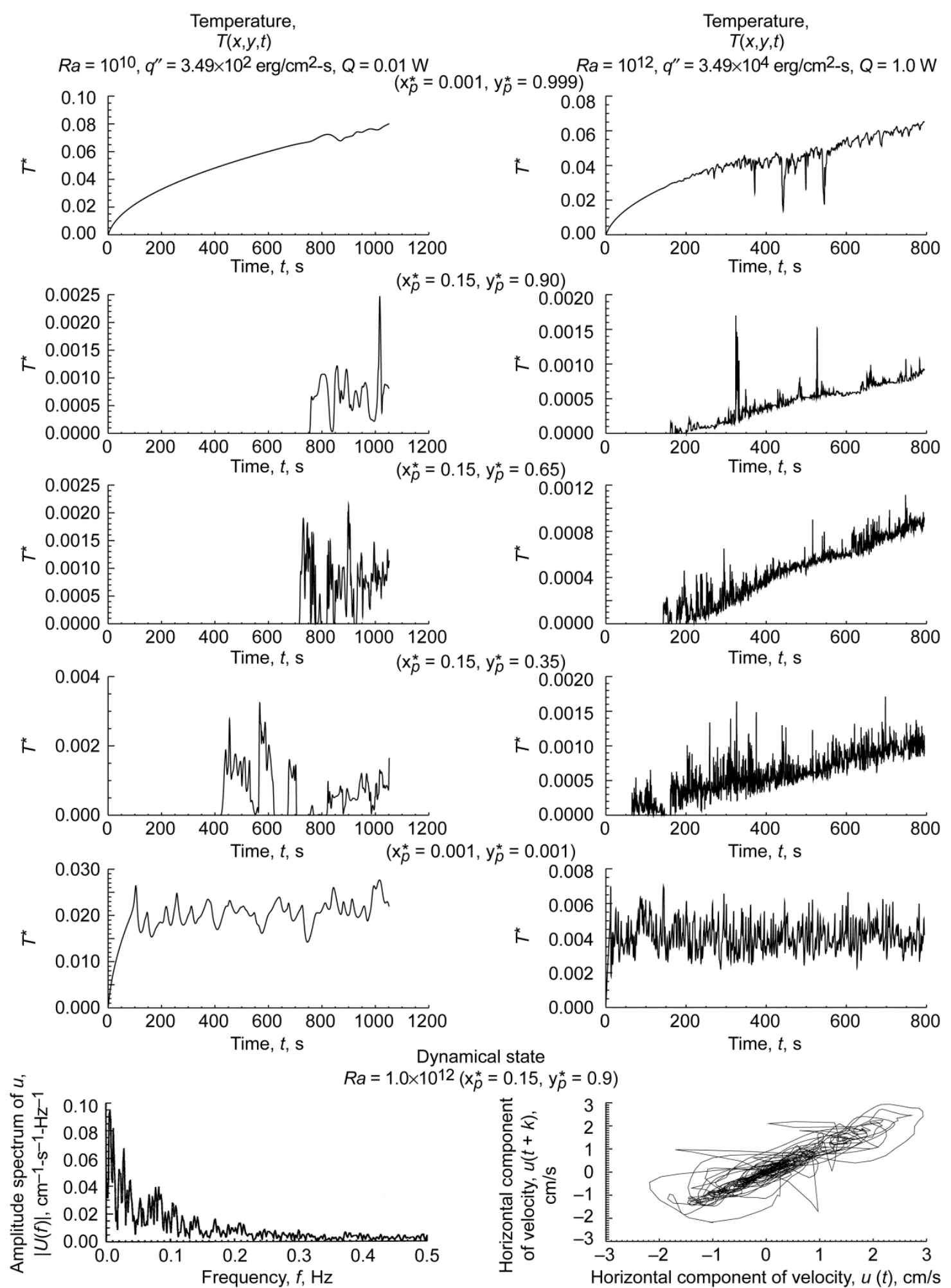

Figure 12.-Comparison of low (heat load, $Q=0.01 \mathrm{~W}$, and heat flux ratio at the sidewall, $f_{s}=2.87 \times 10^{-6}$ ) and moderate $\left(Q=1.0 \mathrm{~W}\right.$ and $\left.f_{s}=2.87 \times 10^{-8}\right)$ heat absorption from the ambient environment on penetrative convective instability along the height of the enclosure, as well as the typical dynamical state for Rayleigh number, $R a=10^{12}$; aspect ratio, $A r=3.24$ (height and length of enclosure, $H=69.1 \mathrm{~cm}$ and $L=19.1 \mathrm{~cm}$ ); Prandtl number, $\operatorname{Pr}=2.27$; and heat flux ratios at bottom and top of enclosure, $f_{b}=1$ and $f_{t}=1$, respectively. $T$, temperature; $t$, time; $q^{\prime \prime}$, heat flux; $k$, constant. Results are shown at different points inside the enclosure $\left(x_{p}^{*}, y_{p}^{*}\right)$. 
complexity of an experiment, we conjecture that there could be uncertainty associated with the delay time $\tau_{D}$ for penetrative convection that cannot be captured in an experimental system. Nevertheless, as is shown in Section 4.6, the temperature magnitude over the time scale of the experiment, $t=600 \mathrm{~s}$, indicates that the absorption of a heat load of $Q=1.0 \mathrm{~W}$ from the background environment can serve as a lower bound for a potential scenario of the actual experiment. These results imply that the temperature signals from an experimental system, prior to averaging, are likely to be nonstationary, with a mean value that varies with time; for the experimental system (Refs. 1 and 2) considered, only averaged values of temperature were reported. A nonstationary time series requires proper treatment of the mean value (Ref. 12). Without proper averaging of a nonstationary time series, uncertainty can be introduced in the average value of temperatures.

The time series shown for $R a=10^{12}$ at $y_{p}^{*}=0.9$ is quantified using the amplitude spectrum of the $u$ component of the velocity field, defined as

$$
\tilde{U}(f)=\frac{1}{T_{R}}\left|\int_{0}^{T_{R}} u(t) e^{-2 \pi i f t}\right|
$$

In relation to Figure 12 showing the dynamical state for $R a=10^{12}$, Equation (24) shows the square root of the local kinetic energy per unit time, or the square root of power $\left(P_{u}(f)\right)$ along the ordinate axis; the abscissa represents the spectrum of the frequency of the time signal; and $T_{R}$ denotes the interval of the time series. A convolution relationship, $U(f)=W_{H}(f) * \tilde{U}(f)$, using a Hanning spectral window $W_{H}(f)$ is used to obtain a smooth estimate $U(f)$. The frequency decomposition of $U(f)$ in Figure 12 indicates a long-period event that has a low-frequency peak of $0.005 \mathrm{~Hz}$ and spans a broadband of $0.5 \mathrm{~Hz}$. The broadband response falls below the critical Nyquist frequency of $f_{c}=3.5 \mathrm{~Hz}$, indicating that the effective bandwidth of the signal is free from aliasing. Note that the power spectrum, $P_{u}(f)=U(f) \times U^{*}(f) / 2 \pi$, is the product of $U(f)$ with its conjugate $U^{*}(f)$, which in terms of Equation (24) is the square of the magnitude of the Fourier-transformed velocity component $u(t)$. The power spectrum gives results that are similar to those for the amplitude spectrum. However, the amplitude spectrum was found to have the advantage of showing the higher harmonics of the fundamental frequency on a linear scale. A pseudophase space trajectory, obtained by lagging the time signal of $u(t+k)$ by a constant value $k$, shows a dense trajectory. The combination of a broadband power spectrum and a dense pseudophase space trajectory indicates a chaotic state. We conjecture that this chaotic dynamical state exists for the entire range of Rayleigh numbers considered — even for the lowest heat absorption $(Q=0.001 \mathrm{~W})$ at $R a=10^{9}$ owing to the large size of the enclosure.

Related works on liquid helium by Behringer (Ref. 13) aimed at characterizing the onset of lowdimensional turbulence or chaos show that the trend of the critical Rayleigh number as a function of aspect ratio merges with the prediction of Charlson and Sani (Refs. 14 and 15) for long vertical walls, which shows an increase of the critical Rayleigh number for the onset of instability. In contrast, enclosures with large horizontal extent show that turbulence occurs near the critical Rayleigh number. These observations parallel our conjecture of chaos at the lowest Rayleigh number since our enclosure has relatively long vertical and horizontal length scales.

\subsection{Comparison of Model With Experiment}

Figure 13 compares the mean fluctuating temperature $\bar{T}$ at fixed points $\left(x_{p}, y_{p}\right)$ along the height of the enclosure with experimental data (Experiments (Exp.) — no screen, no heater) after Bolshinskiy et al. (Ref. 1). The model uses the boundary condition of heat load from $Q=1.0$ to $10 \mathrm{~W}\left(R a=10^{12}\right.$ to $\left.10^{13}\right)$ due to heat absorption from the ambient laboratory environment. The experimental data (o) correspond to average values of temperatures $\langle T>$ for five points over a plane at each height $(y)$ location. We compare the experimental data with the mean temperature $\bar{T}$ at a fixed location in order to show unfiltered 
predicted temperatures without plane averaging; note the unfiltered temperatures in Figures 11 and 12 reveal inherent fluctuations that may not be captured by averaging. The experimental data points are in close proximity to the computational model, and for comparison, the figures show data for a long time, $t=600 \mathrm{~s}$ at $R a=10^{12}$, and a short time, $t=50 \mathrm{~s}$ for $R a=10^{13}$. Note that the delay time $\tau_{D}=15 \mathrm{~s}$ for $R a=10^{13}$ is very short for high heat flux absorption and falls within the response time of the experimental data. For $R a=10^{12}$, a heat load of $Q=1 \mathrm{~W}$ yields temperature magnitudes that are lower than those measured in the bulk liquid; however, in the boundary layer near the top wall, the mean temperature, $\bar{T}=79.5 \mathrm{~K}$, approaches the bulk experimental temperature, $<T>=80.8 \mathrm{~K}$, of the liquid in the middle region.

The model predicts the trend shown by the data: that is, a nearly uniform temperature in the central region of the enclosure, a nearly adverse temperature gradient near the bottom of the enclosure due to local convective instability, and a stable temperature gradient near the top region due to stable stratification. For an ambient heat load of $Q=10 \mathrm{~W}\left(R a=10^{13}\right)$ in the neighborhood of the maximum value estimated from thermal radiation due to the background laboratory environment $\left(T_{\infty}=293 \mathrm{~K}\right)$, the saturation temperature of liquid nitrogen, $T_{A}=77 \mathrm{~K}$, nearly matches the experimental data for short times. In this case, the temperature in the boundary layer near the bottom wall, $\bar{T}=77.5 \mathrm{~K}$, nearly matches the highest temperature measured experimentally near the top region, $<T>=77.6 \mathrm{~K}$. In contrast, the temperature in the boundary layer near the top wall, $\bar{T}=83.5 \mathrm{~K}$, exceeds the highest measured temperature in the top region, $\angle T>=82 \mathrm{~K}$, for the long duration time of $t=600 \mathrm{~s}$. Given the potential uncertainty associated with establishing the proper initial condition that can occur for experimental systems, a minimum-tomaximum heat load range due to a background environment of $Q=1$ to $10 \mathrm{~W}\left(R a=10^{12}\right.$ to $\left.10^{13}\right)$ can be representative of actual experimental conditions.
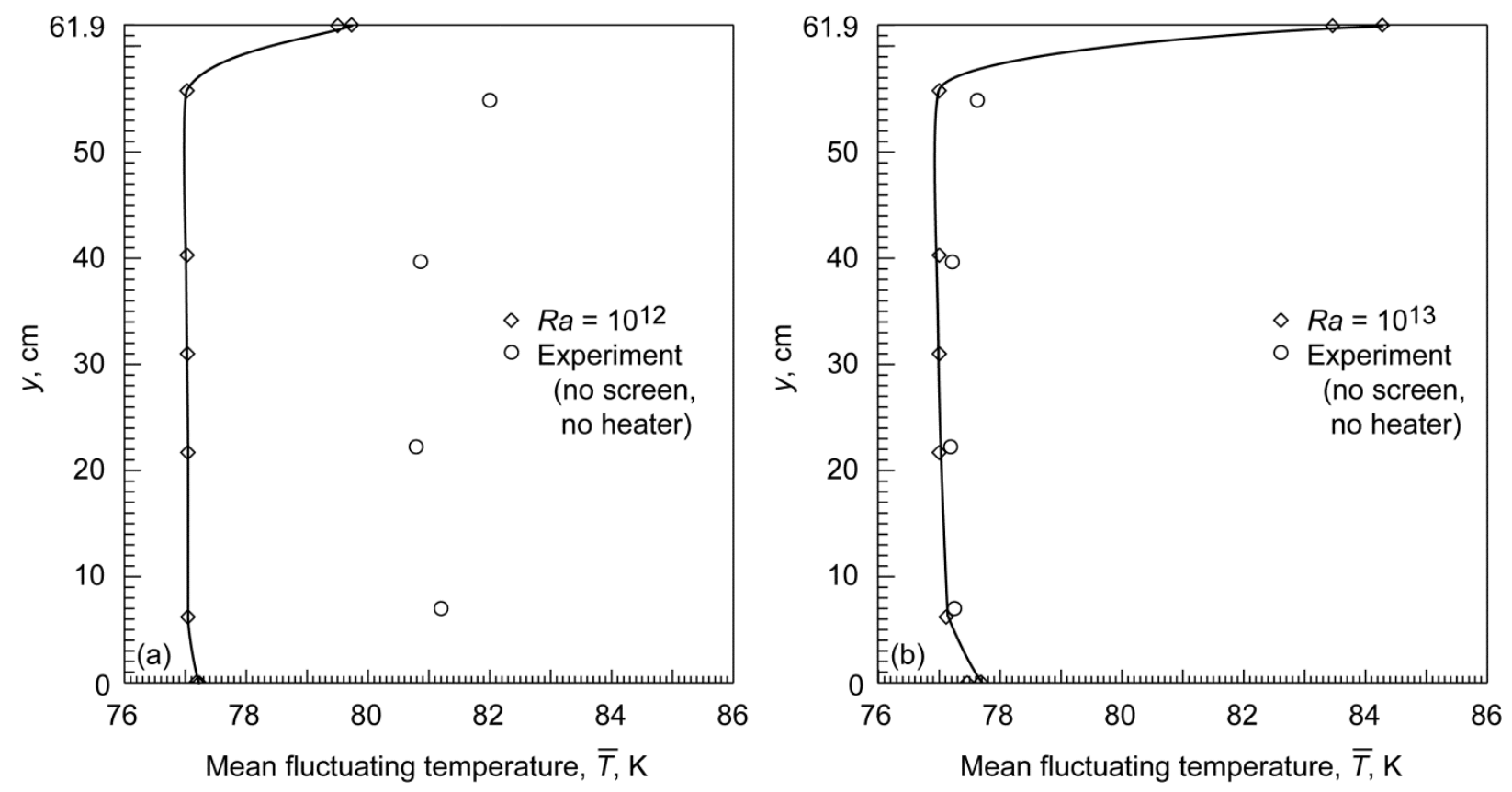

Figure 13.-Comparison of mean fluctuating temperature $\bar{T}$ at fixed points $\left(x_{p}, y_{p}\right)$ in the flow field with experimental data (Exp.- no screen and no heater) (Ref. 1) for increasing Rayleigh numbers, Ra. (a) Time, $t=600 \mathrm{~s}$. (b) Time, $t=50 \mathrm{~s}$. 


\subsection{Summary and Conclusion}

A model problem is addressed on the effect of heat absorption from the background laboratory environment on the temperature rise of liquid nitrogen at saturation conditions $\left(\rho_{A}, T_{A}\right)$ inside a large enclosure $(H=61.9 \mathrm{~cm}$ and $L=19.1 \mathrm{~cm})$. The model contributes toward an understanding of the flow field dynamics for an experimental system aimed at investigating heat entrapment effects in liquid acquisition devices. For estimated background heat load conditions, we consider a range from $Q=0.001$ to $10 \mathrm{~W}$, corresponding to Rayleigh numbers from $R a=10^{9}$ to $10^{13}$. The estimated heat flux of the top and bottom boundaries $\left(q_{t}^{\prime \prime}=q_{b}^{\prime \prime}\right)$ ranges from $3.49 \times 10^{1}$ to $3.49 \times 10^{5} \mathrm{erg} / \mathrm{cm}^{2}-\mathrm{s}$, and a conservative estimate of $q_{s}^{\prime \prime}=0.001 \mathrm{erg} / \mathrm{cm}^{2}$-s is used for the sidewalls owing to the use of insulation at the side boundary in the experiments. In response to heat load, the flow field dynamics for $R a=10^{9}$ to $10^{13}$ show self-similarity. The flow field is driven by local convective instability, against a free convection base flow, generated at the bottom of the enclosure. The flow field shows small-scale thermals for the short time scale and a traveling-wave-type motion of convective modes for the long time scale.

Finite heat leakage at the sidewalls generates the initial free-convection base flow, which consists of two counterrotating cells that become unstable against convective instability caused by an adverse temperature gradient at the bottom boundary, while the top boundary forms a stably stratified configuration. A number of modes arise, depending on the Rayleigh number, which self-organize into two modes owing to amalgamation prior to the propagation of the convective instability along the height of the enclosure. A number of symmetric vertical modes arise; these modes become asymmetric prior to reaching the top of the enclosure depending on the Rayleigh number. A traveling-wave-type motion of convective modes follows that generates aperiodic oscillations of the flow and temperature fields and is representative of the asymptotic dynamics.

The time history of the temperature and velocity fields shows a characteristic delay time $\tau_{D}$ for the penetration of the convective instability along the height of the enclosure due to heat load absorption. The estimated heat loads, which serve as lower and upper bounds, owing to the background environment range from $Q=1$ to $10 \mathrm{~W}$, and show agreement with experimental trends $\left(R a=10^{12}\right.$ to $\left.10^{13}\right)$. For heat loads from $Q=1$ to $10 \mathrm{~W}$, the time signal is nonstationary over a time band and spatial location range, with a mean that increases with time. Thus, cautionary measures should be taken for averaging of nonstationary temperature measurements. A chaotic dynamical state (stochastic time signal) seems to be the norm for the range of Rayleigh numbers considered, $R a=10^{9}$ to $10^{13}$, owing to the large size of the enclosure.

The computational model sheds light on temperature measurements of saturated liquid nitrogen inside an enclosure subjected to an unknown heat load from a background laboratory environment for application to liquid acquisition devices. To understand the effect of the applied heat flux at the bottom of the enclosure on the temperature rise of liquid nitrogen, it is necessary to establish the base condition of the experiment. This base condition, which was characterized experimentally by measurements of the temperature rise due to the background environment (Exp.- no screen, no heater) can be used to establish the boundary conditions. The computational model shows that the boundary conditions for the experiment lie between $Q=1$ and $10 \mathrm{~W}\left(R a=10^{12}\right.$ and $\left.10^{13}\right)$. These established boundary conditions can be used as input for the top heat flux $q_{t}^{\prime \prime}$ along with the estimated side heat flux $q_{s}^{\prime \prime}$ in order to analyze the next phase of the experiment, that is, the effect of independent variation of the bottom heat flux $q_{b}^{\prime \prime}$. This implies that a bottom heat-load variation from a minimum of $Q=10 \mathrm{~W}$ to the maximum experimental input of $Q=104 \mathrm{~W}$ can be investigated. 


\section{Symbols}

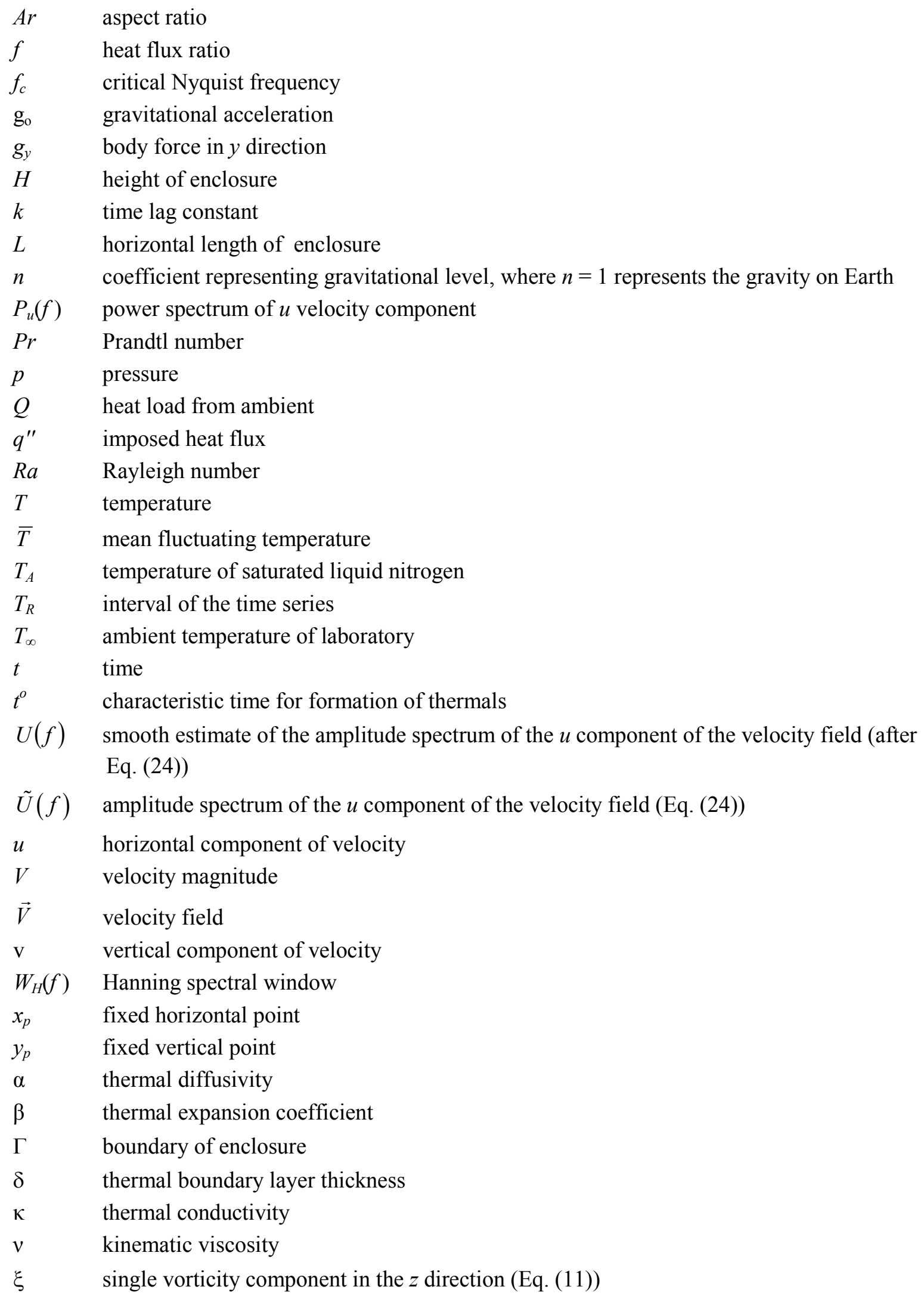




$\begin{array}{ll}\rho & \text { density } \\ \rho_{A} & \text { density of the saturated liquid nitrogen } \\ \tau_{D} & \text { delay time } \\ \psi & \text { stream function } \\ \forall & \text { for all } \\ \nabla & \text { gradient operator } \\ \Lambda & \text { parametric set (Eq. (22)) } \\ \Lambda^{\prime} & \text { reduced parametric set (Eq. (23)) } \\ || & \text { magnitude }\end{array}$

\section{Subscripts:}

b bottom

$p \quad$ pressure (after Eq. (3))

$s \quad$ sidewall

$t$ top

\section{Superscripts:}

* dimensionless quantity 


\section{References}

1. Bolshinskiy, L.G., et al.: Capillary Liquid Acquisition Device Heat Entrapment. NASA/TM-2007215074, 2007. http://ntrs.nasa.gov/

2. Bolshinskiy, L.G.; Hastings, L.J.; and Statham, G.: Cryogenic Capillary Screen Heat Entrapment. Cryogenics, vol. 48, no. 5, 2008, pp. 232-237.

3. Duval, W.M.B.; Chato, D.J.; and Doherty, M.P.: Heat Entrapment Effects Within Liquid Acquisition Devices. AIAA 2010-1298, 2010.

4. Townsend, A.A.: Temperature Fluctuations Over a Heated Horizontal Surface. J. Fluid Mech., vol. 5, no. 2, 1959 , pp. 209-241.

5. Howard, L.N.: Convection at High Rayleigh Number. Applied Mechanics, Henry Gortler, ed., Springer-Verlag, Berlin, 1966, pp. 1109-1115.

6. Elder, J.W.: Steady Free Convection in a Porous Medium Heated From Below. J. Fluid Mech., vol. 27, no. 1, 1967, pp. 29-48.

7. Elder, J.W.: Transient Convection in a Porous Medium. J. Fluid Mech., vol. 27, no. 3, 1967, pp. 609-623.

8. Elder, J.W.: The Unstable Thermal Interface. J. Fluid Mech., vol. 32, no. 1, 1968, pp. 69-96.

9. Elder, J.W.: The Temporal Development of a Model of High Rayleigh Number Convection. J. Fluid Mech., vol. 35, no. 3, 1969, pp. 417-437.

10. Deardorff, J.W.; and Willis, G.E.: The Effect of Two-Dimensionality on the Suppression of Thermal Turbulence. J. Fluid Mech., vol. 23, no. 2, 1965, pp. 337-353.

11. Sparrow, E.M.; Husar, R.B.; and Goldstein, R.J.: Observation and Other Characteristics of Thermals. J. Fluid Mech., vol. 41, no. 4, 1970, pp. 793-800.

12. Wei, William W.S.: Time Series Analysis: Univariate and Multivariate Methods. Addison-Wesley Publishing, 1990, pp. 67-84.

13. Behringer, R.P.: Rayleigh-Bénard Convection and Turbulence in Liquid Helium. Rev. Mod. Phys., vol. 57, no. 3, Part 1, 1985, pp. 657-687.

14. Charlson, G.S.; and Sani, R.L.: Thermoconvective Instability in a Bounded Cylindrical Fluid Layer. Int. J. Heat Mass Transfer, vol. 13, no. 9, 1970, pp. 1479-1496.

15. Charlson, G.S.; and Sani, R.L.: On Thermoconvective Instability in a Bounded Cylindrical Fluid Layer. Int. J. Heat Mass Transfer, vol. 14, no. 12, 1971, pp. 2157-2160. 


\begin{tabular}{|c|c|c|c|c|c|}
\hline \multicolumn{5}{|c|}{ REPORT DOCUMENTATION PAGE } & $\begin{array}{l}\text { Form Approved } \\
\text { OMB No. 0704-0188 }\end{array}$ \\
\hline \multicolumn{6}{|c|}{$\begin{array}{l}\text { The public reporting burden for this collection of information is estimated to average } 1 \text { hour per response, including the time for reviewing instructions, searching existing data sources, gathering and } \\
\text { maintaining the data needed, and completing and reviewing the collection of information. Send comments regarding this burden estimate or any other aspect of this collection of information, including } \\
\text { suggestions for reducing this burden, to Department of Defense, Washington Headquarters Services, Directorate for Information Operations and Reports (0704-0188), } 1215 \text { Jefferson Davis Highway, Suite } \\
1204, \text { Arlington, VA } 22202-4302 \text {. Respondents should be aware that notwithstanding any other provision of law, no person shall be subject to any penalty for failing to comply with a collection of information if it } \\
\text { does not display a currently valid OMB control number. } \\
\text { PLEASE DO NOT RETURN YOUR FORM TO THE ABOVE ADDRESS. }\end{array}$} \\
\hline \multicolumn{2}{|c|}{$\begin{array}{l}\text { 1. REPORT DATE (DD-MM-YYYY) } \\
01-06-2014\end{array}$} & \multicolumn{3}{|c|}{$\begin{array}{l}\text { 2. REPORT TYPE } \\
\text { Technical Memorandum }\end{array}$} & 3. DATES COVERED (From - To) \\
\hline \multicolumn{5}{|c|}{$\begin{array}{l}\text { 4. TITLE AND SUBTITLE } \\
\text { Transient Convection Due to Imposed Heat Flux: Application to Liquid-Acquisition } \\
\text { Devices }\end{array}$} & 5c. PROGRAM ELEMENT NUMBER \\
\hline \multirow{3}{*}{\multicolumn{5}{|c|}{$\begin{array}{l}\text { 6. AUTHOR(S) } \\
\text { Duval, Walter, M.B.; Chato, David, J.; Doherty, Michael, P. }\end{array}$}} & 5d. PROJECT NUMBER \\
\hline & & & & & 5e. TASK NUMBER \\
\hline & & & & & $\begin{array}{l}\text { 5f. WORK UNIT NUMBER } \\
\text { WBS 095240.04.03.03.01.03 }\end{array}$ \\
\hline \multicolumn{5}{|c|}{$\begin{array}{l}\text { 7. PERFORMING ORGANIZATION NAME(S) AND ADDRESS(ES) } \\
\text { National Aeronautics and Space Administration } \\
\text { John H. Glenn Research Center at Lewis Field } \\
\text { Cleveland, Ohio 44135-3191 }\end{array}$} & $\begin{array}{l}\text { 8. PERFORMING ORGANIZATION } \\
\text { REPORT NUMBER } \\
\text { E-17597 }\end{array}$ \\
\hline \multirow{2}{*}{\multicolumn{5}{|c|}{$\begin{array}{l}\text { 9. SPONSORING/MONITORING AGENCY NAME(S) AND ADDRESS(ES) } \\
\text { National Aeronautics and Space Administration } \\
\text { Washington, DC 20546-0001 }\end{array}$}} & $\begin{array}{l}\text { 10. SPONSORING/MONITOR'S } \\
\text { ACRONYM(S) } \\
\text { NASA }\end{array}$ \\
\hline & & & & & $\begin{array}{l}\text { 11. SPONSORING/MONITORING } \\
\text { REPORT NUMBER } \\
\text { NASA/TM-2014- } 217442\end{array}$ \\
\hline \multicolumn{6}{|c|}{$\begin{array}{l}\text { 12. DISTRIBUTION/AVAILABILITY STATEMENT } \\
\text { Unclassified-Unlimited } \\
\text { Subject Categories: } 31 \text { and } 34 \\
\text { Available electronically at http://WWw.sti.nasa.gov } \\
\text { This publication is available from the NASA Center for AeroSpace Information, 443-757-5802 }\end{array}$} \\
\hline \multicolumn{6}{|c|}{ 13. SUPPLEMENTARY NOTES } \\
\hline \multicolumn{6}{|c|}{$\begin{array}{l}\text { 14. ABSTRACT } \\
\text { A model problem is considered that addresses the effect of heat load from an ambient laboratory environment on the temperature rise of } \\
\text { liquid nitrogen inside an enclosure. This model has applications to liquid acquisition devices inside the cryogenic storage tanks used to } \\
\text { transport vapor-free propellant to the main engine. We show that heat loads from } Q=0.001 \text { to } 10 \mathrm{~W} \text {, with corresponding Rayleigh numbers } \\
\text { from } R a=10^{9} \text { to } 10^{13} \text {, yield a range of unsteady convective states and temperature rise in the liquid. The results show that } Q=1 \text { to } 10 \mathrm{~W} \\
\left(\mathrm{Ra}=10^{12} \text { to } 10^{13}\right) \text { yield temperature distributions along the enclosure height that are similar in trend to experimental measurements. } \\
\text { Unsteady convection, which shows self-similarity in its planforms, is predicted for the range of heat-load conditions. The onset of } \\
\text { convection occurs from a free-convection-dominated base flow that becomes unstable against convective instability generated at the bottom } \\
\text { of the enclosure while the top of the enclosure is convectively stable. For the higher Rayleigh numbers, } 10^{12} \text { to } 10^{13} \text {, there is a transition } \\
\text { from a stationary to a nonstationary response time signal of the flow and temperature fields with a mean value that increases with time over } \\
\text { various time bands and regions of the enclosure. }\end{array}$} \\
\hline \multicolumn{6}{|c|}{$\begin{array}{l}\text { 15. SUBJECT TERMS } \\
\text { Cryogenics; Thermal instability; Buoyancy-driven flow; Natural convection }\end{array}$} \\
\hline \multicolumn{3}{|c|}{ 16. SECURITY CLASSIFICATION OF: } & \multirow{3}{*}{$\begin{array}{l}\text { 17. LIMITATION OF } \\
\text { ABSTRACT } \\
\text { UU }\end{array}$} & \multirow{3}{*}{$\begin{array}{l}\text { 18. NUMBER } \\
\text { OF } \\
\text { PAGES } \\
32\end{array}$} & 19a. NAME OF RESPONSIBLE PERSON \\
\hline \multirow{2}{*}{$\begin{array}{l}\text { a. REPORT } \\
\text { U }\end{array}$} & \begin{tabular}{|l} 
b. ABSTRACT \\
\end{tabular} & \multirow{2}{*}{$\begin{array}{l}\text { c. THIS PAGE } \\
\mathrm{U}\end{array}$} & & & STI Help Desk (email:help@sti.nasa.gov) \\
\hline & $\mathrm{U}$ & & & & $\begin{array}{l}\text { 19b. TELEPHONE NUMBER (include area code) } \\
443-757-5802\end{array}$ \\
\hline
\end{tabular}



